\title{
Quantifying local ecological knowledge to model historical abundance of long-lived, heavily-exploited fauna
}

\author{
Michelle-María Early-Capistrán ${ }^{1}$, Elena Solana-Arellano ${ }^{\text {Corresp., }}{ }^{2}$, F Alberto Abreu-Grobois ${ }^{3}$, Nemer E Narchi ${ }^{4}$, \\ Gerardo Garibay-Melo ${ }^{5}$, Jeffrey A. Seminoff ${ }^{6}$, Volker Koch ${ }^{7}$, Andrea Saenz-Arroyo ${ }^{8}$ \\ 1 Posgrado en Ciencias del Mar y Limnología, Universidad Nacional Autónoma de México, Mexico City, Mexico \\ 3 Instituto de Ciencias del Mar y Limnología - Unidad Académica Mazatlán, Universidad Nacional Autónoma de México, Mazatlán, Sinaloa, Mexico \\ 4 CoLaboratorio de Oceanografía Social/Centro de Estudios de Geografía Humana, El Colegio de Michoacán - Sede La Piedad, La Piedad, Michoacán \\ Mexico \\ 5 Posgrado en Manejo de Ecosistemas de Zonas Áridas, Universidad Autónoma de Baja California, Ensenada, Baja California, Mexico \\ 6 NOAA - Southwest Fisheries Science Center, La Jolla, California, United States \\ 7 Deutsche Gesellschaft für Internationale Zusammenarbeit (GIZ) GmbH, Bonn, Germany, Bonn, Germany \\ 8 Departamento de Conservación de la Biodiversidad, El Colegio de la Frontera Sur (ECOSUR), San Cristobal de las Casas, Chiapas, Mexico \\ Corresponding Author: Elena Solana-Arellano \\ Email address: esolana@cicese.mx
}

Deriving robust historical population trends for long-lived species subject to human exploitation is challenging in scenarios where long-term scientific data are scarce or unavailable, as often occurs for species affected by small-scale fisheries and subsistence hunting. The importance of Local Ecological Knowledge (LEK) in data-poor scenarios is increasingly recognized in conservation, both in terms of uncovering historical trends and for engaging community stewardship of historic information. Building on previous work in marine historical ecology and local ecological knowledge, we propose a mixed socioecological framework to reliably document and quantify LEK to reconstruct historical population trends. Our method can be adapted by interdisciplinary teams to study various long-lived taxa with a history of human use. We demonstrate the validity of our approach by reconstructing long-term abundance data for the heavily-exploited East Pacific green turtle (Chelonia mydas) in Baja California, Mexico, which was driven to near extinction by a largely unregulated fishery from the early 1950s to the 1980s. No scientific baseline abundance data were available for this time-frame because recent biological surveys started in 1995 after all green turtle fisheries in the area were closed. To fill this data gap, we documented LEK among local fishers using ethnographic methods and obtained verified, qualitative data to understand the socio-environmental complexity of the green turtle fishery. We then established an iterative framework to synthesize and quantify LEK using generalized linear models (GLMs) and nonlinear regression (NLR) to generate a standardized, LEK-derived catch-per-unit-effort (CPUE) time-series. CPUE is an index of 
abundance that is compatible with contemporary scientific survey data. We confirmed the accuracy of LEK-derived CPUE estimates via comparisons with fisheries statistics available for 1962-1982. We then modeled LEK-derived abundance trends prior to 1995 using NLR. Our model established baseline abundance and described historical declines, revealing that the most critical (exponential) decline occurred between 1960 and 1980 . This robust integration of LEK data with ecological science is of critical value for conservation and management, as it contributes to a holistic view of a species' historic and contemporary conservation status. 


\section{Quantifying Local Ecological Knowledge to Model Historical Abundance of}

\section{Long-lived, Heavily-Exploited Fauna}

4 Michelle María Early-Capistrán ${ }^{1}$, Elena Solana-Arellano², F. Alberto Abreu-Grobois ${ }^{3}$, Nemer E.

5 Narchi $^{4}$, Gerardo Garibay-Melo ${ }^{5}$, Jeffrey A. Seminoff ${ }^{6}$, Volker Koch ${ }^{7}$, Andrea Sáenz-Arroyo ${ }^{8}$

$7{ }^{1}$ Posgrado en Ciencias del Mar y Limnología, Universidad Nacional Autónoma de México, 8 Mexico City, Mexico

92 Departamento de Ecología Marina, Centro de Investigación Científica y Educación Superior de 10 Ensenada, Ensenada, Baja California, Mexico.

113 Instituto de Ciencias del Mar y Limnología - Unidad Académica Mazatlán, Universidad 12 Nacional Autónoma de México, Mazatlán, Sinaloa, Mexico.

$13{ }^{4}$ CoLaboratorio de Oceanografía Social/Centro de Estudios de Geografía Humana, El Colegio 14 de Michoacán - Sede La Piedad, La Piedad, Michoacán, Mexico

155 Posgrado en Manejo de Ecosistemas de Zonas Áridas. Universidad Autónoma de Baja 16 California, Ensenada, B.C., Mexico.

$17{ }^{6}$ NOAA - Southwest Fisheries Science Center, La Jolla, California, U.S.A.

$18{ }^{7}$ Deutsche Gesellschaft für Internationale Zusammenarbeit (GIZ) GmbH, Bonn, Germany

$19{ }^{8}$ Departamento de Conservación de la Biodiversidad. El Colegio de la Frontera Sur (ECOSUR), 20 San Cristóbal de Las Casas, Chiapas, Mexico

Corresponding Author: Elena Solana-Arellano ${ }^{2}$

Departamento de Ecología Marina, Centro de Investigación Científica y Educación Superior de Ensenada, Carretera Ensenada-Tijuana No. 3918, Zona Playitas, 22860, Ensenada, Baja California, Mexico

26 Email address: esolana@,cicese.mx 


\section{Abstract}

28 Deriving robust historical population trends for long-lived species subject to human exploitation

29 is challenging in scenarios where long-term scientific data are scarce or unavailable, as often

30 occurs for species affected by small-scale fisheries and subsistence hunting. The importance of

31 Local Ecological Knowledge (LEK) in data-poor scenarios is increasingly recognized in

32 conservation, both in terms of uncovering historical trends and for engaging community

33 stewardship of historic information. Building on previous work in marine historical ecology and

34 local ecological knowledge, we propose a mixed socio-ecological framework to reliably

35 document and quantify LEK to reconstruct historical population trends. Our method can be

36 adapted by interdisciplinary teams to study various long-lived taxa with a history of human use.

37 We demonstrate the validity of our approach by reconstructing long-term abundance data for the

38 heavily-exploited East Pacific green turtle (Chelonia mydas) in Baja California, Mexico, which

39 was driven to near extinction by a largely unregulated fishery from the early 1950 s to the 1980 s.

40 No scientific baseline abundance data were available for this time-frame because recent

41 biological surveys started in 1995 after all green turtle fisheries in the area were closed. To fill

42 this data gap, we documented LEK among local fishers using ethnographic methods and

43 obtained verified, qualitative data to understand the socio-environmental complexity of the green

44 turtle fishery. We then established an iterative framework to synthesize and quantify LEK using

45 generalized linear models (GLMs) and nonlinear regression (NLR) to generate a standardized,

46 LEK-derived catch-per-unit-effort (CPUE) time-series. CPUE is an index of abundance that is

47 compatible with contemporary scientific survey data. We confirmed the accuracy of LEK-

48 derived CPUE estimates via comparisons with fisheries statistics available for 1962-1982. We

49 then modeled LEK-derived abundance trends prior to 1995 using NLR. Our model established 
50 baseline abundance and described historical declines, revealing that the most critical

51 (exponential) decline occurred between 1960 and 1980. This robust integration of LEK data with

52 ecological science is of critical value for conservation and management, as it contributes to a

53 holistic view of a species' historic and contemporary conservation status.

\section{Introduction}

Assessment of the current population status of long-lived species benefits from a firm understanding of historical baseline abundances (Pauly, 1995). For example, the Internation Union for Conservation of Nature (IUCN) Red List criteria requires abundance trends over three generations. For long-lived species, tracking three generations may necessitate $>100$ years of data (Seminoff \& Shanker, 2008; IUCN, 2019). However, deriving robust historical population trends is challenging when scientific monitoring data are scarce or unavailable (Pauly, 1995; Sáenz-Arroyo et al., 2005; Beaudreau \& Levin, 2014). This is further aggravated in data-poor contexts, when a species is impacted by illegal, unreported, or unregulated exploitation. Common data-poor contexts include small-scale fisheries and subsistence hunting (Moller et al., 2004; Duffy et al., 2016; Selgrath, Gergel \& Vincent, 2018). This challenging situation has led to increased interest in Local Ecological Knowledge (LEK), including traditional knowledge (TK)

67 of indigenous peoples, to better understand long-term environmental change and humanenvironment interactions (Johannes, 1981; Castro et al., 2014; Bao \& Drew, 2017; Lee et al., 2018; Barrios-Garrido et al., 2018). about their surrounding environments and biota (Bélisle et al., 2018). LEK does not require that 
72 knowledge-holders be indigenous, nor embedded in a broader shared culture, and thus can be

73 applied to people and communities with relatively short histories of interactions with a specific

74 environment (cf. Narchi et al., 2014). LEK data have been used in combination with official

75 records and historical documentation to reconstruct long-term abundance trends of exploited

76 marine species in multiple contexts (Jackson et al., 2001; Sáenz-Arroyo et al., 2005; Beaudreau

77 \& Levin, 2014; Lee et al., 2018). LEK also provides baseline data that fill knowledge gaps which

78 cannot be addressed through natural sciences alone (Mukherjee et al., 2018; Mason et al., 2019).

79 Examples include knowledge of ecological change over broad time-scales (Sáenz-Arroyo et al.,

80 2005; Lee et al., 2018), traditional and local resource use (Johannes, 1981; Barrios-Garrido et al.,

81 2018), and conceptual frameworks for ecological modeling (Ainsworth, 2011; Bélisle et al.,

82 2018). However, clear methodological guidelines, based on robust methods from social and

83 natural sciences, are needed to reliably integrate LEK with scientific ecological data in

84 conservation science (Mukherjee et al., 2018; Young et al., 2018; Moon et al., 2019). This

85 includes developing approaches to collate and validate information from diverse knowledge

86 sources, and forming interdisciplinary teams with expertise appropriate for the methods being

87 used (St. John et al., 2014; Sutherland et al., 2018).

88 We present a case study of the East Pacific green turtle (Chelonia mydas, hereafter green

89 turtle) in Bahía de los Ángeles (BLA), Baja California, Mexico, to demonstrate a novel

90 framework that can be adapted to long-lived, exploited taxa to evaluate abundance trends in data-

91 poor scenarios. We used ethnography to document LEK, and developed an ad hoc

92 epistemological approach to synthesize and quantify LEK data using generalized linear models

93 (GLMs) and nonlinear least squares regression (NLR) to reconstruct long-term C. mydas 
94 abundance. Our model established baseline abundance, described historical declines, and

95 evaluated how human impacts contributed to current species population status.

96 The complexity of the green turtle's life history makes it particularly challenging to evaluate

97 its conservation status. Generation times are up to 50 years, they are highly migratory, and life

98 stages occupy multiple habitats separated by hundreds or thousands of kilometers, often in

99 different countries. Globally, abundance data are skewed towards nesting beaches, which only

100 quantify nesting females (Seminoff \& Shanker, 2008; Godley et al., 2010). For the Eastern

101 Pacific population, nesting data have been collected since 1980 at the primary nesting beach in

102 Colola, Michoacán, Mexico ( 1500 km from BLA) (Delgado-Trejo, 2016). However, there are

103 substantial knowledge gaps for foraging habitats, which are critical for several reasons. Foraging

104 habitats include pre-reproductive life stages — which are the most abundant life stages in the

105 population - along with adults of both sexes. Furthermore, foraging habitats are where green

106 turtles spend the majority of their life: juveniles may spend 20 years or more in foraging grounds

107 until reaching maturity, and adults reside at feeding grounds during non-breeding periods

108 (Seminoff, Resendiz \& Nichols, 2002; Seminoff \& Shanker, 2008; Senko et al., 2019). Thus,

109 expanding data on foraging habitats is of utmost importance for a holistic understanding of

110 population status (Chaloupka et al., 2008; Mazaris et al., 2017; Wildermann et al., 2018).

111 Green turtles are listed as Endangered by the IUCN and Mexican law as a result of

112 population collapse due to a largely unregulated fishery between the 1950s and 1980s (Diario

113 Oficial de la Federación, 1990; IUCN, 2019; SEMARNAT, 2010). Populations in the Eastern

114 Pacific have increased since the early 2000s thanks to decades of nesting beach protection at

115 Colola starting in the late 1970s, coupled with expanded efforts to limit egg harvests, direct

116 captures, and poaching throughout the species' range in Mexico (Delgado-Trejo, 2016; Seminoff 
117 et al., 2015). These efforts were fortified by the 1990 ban on all sea turtle use in Mexico, which

118 established a legal framework to prevent harvests (Diario Oficial de la Federación, 1990;

119 SEMARNAT, 2010). However, abundance data and long-term trends prior to population

120 collapse are needed to contextualize current population levels (Early-Capistrán et al., 2018;

121 Seminoff et al., 2008).

122 Starting with an overarching research question (e.g., What was the baseline green turtle

123 abundance, and how did it change over time, before scientific monitoring?), we carried out

124 background research with natural and social science perspectives to gain a broad understanding

125 of the research topic (Crandall et al., 2018). We then used an iterative approach to document

126 LEK through ethnography, and synthesized LEK-data for integration with ecological modeling

127 to provide a consistent long-term time-series of green turtle abundance data that can inform 128 conservation.

130 Methods

131 We present a flexible approach for generating green turtle abundance estimates from LEK that

132 can be modified for long-lived species with a history of human use. Our approach consists of

133 four phases: (1) background research and experimental design; (2) an iterative process of LEK

134 documentation, synthesis, and quantification; (3) database standardization and validation; and (4)

135 statistical analysis and modeling of the standardized database (Figure 1). Interdisciplinary teams

136 can ensure that quality and reliability standards are met across fields (Tengö et al., 2014; St. John

137 et al., 2014; Sutherland et al., 2018). Detailed accounts of methods and tools are available in

138 Supporting Information (henceforth, SI) (SI: Article S1).

Peer] reviewing PDF | (2019:10:42113:2:1:NEW 11 Jun 2020) 


\section{Phase 1: Background Research and Experimental Design}

\section{1.1 Study site}

142 To demonstrate our methods, we used the case of the green turtle in Bahía de los Ángeles (BLA), 143 Baja California, Mexico (28 $\left.57^{\prime} 6.90^{\prime \prime} \mathrm{N}, 113^{\circ} 33^{\prime} 44.76^{\prime \prime} \mathrm{W}\right)$, an index foraging area in the Gulf of

144 California (Seminoff et al., 2003, 2008). We define an index foraging area as a site that (i) has

145 aggregations of turtles in the marine environment that represent a significant proportion of the

146 regional population, and (ii) has been monitored systematically and constantly over a prolonged

147 period of time ( $>10$ years). In-water scientific monitoring in this foraging area began in 1995, 148 after population collapse (Seminoff et al., 2003, 2008). Contemporary scientific monitoring uses 149 catch-per-unit-effort (CPUE) as a measure of abundance (Seminoff et al., 2008).

151 peninsula since the earliest phases of human occupation at least 12,000 years ago (cf. Early-

152 Capistrán, 2014). From the late 18th century until the early 1950s, green turtle harvests were 153 primarily subsistence-oriented. Turtles were harpooned from small, wooden canoes propelled 154 with oars or paddles. During the 1960 s, the economic and demographic growth along the U.S.155 Mexico border led to an increased market for green turtle meat in Mexican border cities. BLA 156 was a key supplier within this trade, and was able to meet demands as the introduction of 157 outboard motors, fiberglass vessels, and set-nets increased cargo volume and catch efficiency. 158 Additionally, improvement of transport and communication infrastructure facilitated market 159 access (Early-Capistrán et al., 2018). The fishery collapsed in the 1970s, green turtle licenses 
160 were suspended in 1983 as populations reached dangerously low levels, and all sea turtle fishing

161 in Mexico was banned in 1990 (Márquez, 1996; Seminoff et al., 2008).

162

1631.2 Background research

164 This research is part of an on-going collaborative process in the community of BLA which began

165 in 2012 and has included ethnographic and historiographical research related to human-ocean

166 interaction, along with a review of scientific literature (Early-Capistrán et al., 2018). Background

167 research helped define specific research questions, identify challenges in the study design and

168 methods, and develop a general approach for integrating multiple forms of knowledge (Crandall

169 et al., 2018; Early-Capistrán et al., 2018).

170 Historiographical research situates biological questions in a socio-historical context,

171 providing information on a species' past abundance which can be correlated with time-frames,

172 social processes, and management regimes (SI: Article S1) (Crandall et al., 2018; Sáenz-Arroyo

173 et al., 2005). Historiographical research helped us understand human-green turtle interactions in

174 BLA over the past three centuries, identify the early 1960 s as a period when human impacts

175 precipitated a major decline in green turtle abundance in BLA, and establish the early 1950s as a

176 time-frame for reconstructing baseline abundance before large-scale commercial exploitation

177 (Early-Capistrán et al., 2018).

178 Long-term collaboration with the community of BLA was fundamental for previously

179 establishing the rapport and working trust necessary to conduct transdisciplinary research. Long-

180 term engagement has also helped us acquire sensitivity to the cultural context, gain an 
181 understanding of social conditions, and gather locally-relevant information to define research

182 questions and design (Bernard, 2011; Crandall et al., 2018). We also established a network of

183 local collaborators, whom we define as knowledgeable community members willing to share

184 their knowledge and expertise (Crandall et al., 2018). Due to the fact that ecological knowledge

185 is differentially acquired by social actors, we constructed a heterogeneous network of social

186 actors with diverse types of knowledge that, when nested together, construct the ecological

187 knowledge around green turtle abundance (cf. Brown, 2010).

\subsection{Experimental design}

190

Qualitative methodology

191 Ethnography was our primary data-gathering methodology. This holistic approach to the study of

192 social systems uses a varied toolkit to generate both qualitative and quantitative data (Table 1;

193 SI: Article S1; Table S1). Ethnography requires rapport, sensitivity to the cultural context, and

194 developing an understanding of the social system on its own terms. Data are gathered broadly

195 over topic areas and new questions are developed continuously (Bernard, 2011; Early-Capistrán

196 et al., 2018). Ethnography also helps identify biases by analyzing data within a social and

197 historical context (Drury, Homewood \& Randall, 2011). Ethnographic data are systematized,

198 cross-referenced, verified, and subject to analysis and meta-analysis (Bernard, 2011).

199 We chose ethnography because (i) the high degree of socio-environmental complexity 200 required detailed information on diverse topics; (ii) sea turtle fishing is currently illegal in

201 Mexico and its inquiry requires working trust, long-term engagement, and confidentiality; and 
202 (iii) ethnography provides more detailed and reliable information on sensitive issues than is 203 provided by questionnaires (Drury, Homewood \& Randall, 2011; St. John et al., 2014). Research

204 was designed in compliance with the ethical guidelines of the International Society of 205 Ethnobiology (SI: Article S1, Article S2) (International Society of Ethnobiology, 2006) and 206 approved by the Bioethics Committee of the Centro de Investigación Científica y de Educación 207 Superior de Ensenada (Approval Number 2S.3.1).

208 We defined three social groups within the community and documented their knowledge.

209 Fishers who participated in the legal green turtle fishery before 1990 (henceforth, turtle fishers)

210 constituted the target population and provided the majority of specialized LEK related to human-

211 turtle interaction. This group was the main focus of ethnographic research and contributed the

212 majority of the qualitative and numerical data. Key local collaborators - defined as community

213 members with expertise in particular topics - provided important complementary and contextual

214 information on topics such as local history, commerce, or foodways, among others. Finally, we

215 gathered additional complementary data from members of the community at large (henceforth,

216 community members), including fishers' families, green turtle merchants, local authorities,

217 commercial and sport fishers, and conservation workers, to understand and incorporate multiple

218 perspectives. Methods and sample sizes used for each of these groups are discussed in detail in

219 Section 2.1.

220 We designed flexible interview guides for use in semi-structured and in-depth interviews

221 based on previous ethnographic research on sea turtle use in BLA (Early-Capistrán et al., 2018).

222 Interviewers M.M.E.C. and G.G.M. used these guides as a roadmap for the interviews, allowing

223 respondents to be thorough and make associations between questions, and to include new topics

224 and questions according to interview progress (cf. Castro et al., 2014). Interview guides covered 
225 five main topic areas: (1) biographical profile and career history; (2) sea turtle consumption and

226 commerce; (3) trends in sea turtle captures and sizes; (4) spatial distribution of sea turtle fishing;

227 and (5) fishing effort and technology (Box 1). To prompt recollection of dates, questions were

228 associated with important events in local collaborators' lives (SI: Article S1). We piloted

229 questions with local fishers outside the target population $\left(\mathrm{n}_{\text {pilot }}=2\right)$ and constantly refined the

230 questions to ensure that they were locally contextualized and elicited meaningful answers

231 (Bernard, 2011; Drury, Homewood \& Randall, 2011; Young et al., 2018).

232

233 Reconstructing green turtle abundance through collective knowledge

234 Defining an approach to estimate green turtle abundance based on CPUE was a key challenge.

235 Although CPUE is a crude measure of changes in exploited populations (López-Castro et al., 236 2010), we used it because (i) it is the only available metric of current abundance and (ii) CPUE is 237 an accepted proxy for abundance for IUCN Red Listing (IUCN, 2019; O’Donnell, Pajaro \& 238 Vincent, 2010).

239 Adequate assessment of CPUE as a measure of abundance requires detailed understanding of 240 the fishery and the variables that affected it (Moller et al., 2004). The skilled turtle fishers of 241 BLA almost always targeted high-density locations (hot-spots) and aggregations, and thus 242 maximized CPUE by optimizing fishing patterns based on empirical knowledge of 243 environmental conditions and green turtle behavior (Early-Capistrán et al., 2018). Consequently, 244 turtle fishers' expertise allowed for high CPUE events over time despite declining overall 245 abundance (hyper-stability), underscoring the need to (i) account for this non-random search 246 behavior and (ii) understand central CPUE trends rather than exceptional catches (SI: Article S1, 
247 Figure S1) (Anticamara et al., 2011; Early-Capistrán, 2014; Maunder \& Punt, 2004; Selgrath et 248 al., 2018; Walters, 2003).

249 This scenario is challenging, as (i) interviewees' memory of "typical" events may be less 250 accurate than that of salient events and (ii) high variability in CPUE and changes in fishing 251 efficiency can mask overall abundance trends (Maunder \& Punt, 2004; Damasio et al., 2015; 252 Sáenz-Arroyo \& Revollo-Fernández, 2016). Thus, we designed our methodology to calculate 253 CPUE based on multiple sources rather than individual recollections. We also aimed to identify 254 and account for sources of variation in CPUE that could bias proportionality with abundance, 255 and to construct adequate proxies for variables such as spatial distribution of fishing, differences 256 in gear types, and changes in fleet conditions (Walters, 2003; Maunder \& Punt, 2004; 257 Anticamara et al., 2011; Selgrath, Gergel \& Vincent, 2018).

258 We approached CPUE as a component of a holistic dataset on human-environment 259 interaction, and aimed to synthesize quantitative values on the basis of biocultural consensus, 260 which we define as the pooling of information for evaluating shared environmental perceptions 261 constructed by the summation of individual, community, specialist, and holistic types of 262 knowledge. Biocultural consensus is a synergistic, interconnected set of contents and types of 263 knowledge (c.f. Brown, 2010) in which the resulting knowledge is greater than sum of its parts. 264 In this case, we used knowledge from all three social groups (turtle fishers, key local 265 collaborators, and community members) as inputs for constructing biocultural consensus. Our 266 ethnographic research was primarily focused on turtle fishers, who provided the majority of 267 qualitative and numerical data, as well as specialized LEK related to human-turtle interaction. 268 Key local collaborators and community members provided contextual and complementary data 269 (Figure 2). Biocultural consensus helped build conceptual frameworks for modeling, establish 
270 limits and assumptions, estimate model parameters, and validate model outputs (Bélisle et al., 271 2018).

272 As the primary response variable, we aimed to calculate representative values of CPUE 273 during a specific year with the initial definition:

275 For initial inquiry, we used the working definition of one unit effort as one night of fishing $(\sim 12$

276 hours) with either a harpoon or a set-net (Maunder \& Punt, 2004). We continually refined and

277 updated this definition as we gained further information on fishing technology, effort, and 278 efficiency through the iterative feedback process between qualitative data, NLR, and GLMs 279 (Phase 2). We then standardized CPUE estimates to account for differences in gears and changes 280 in efficiency (Phase 3). As the final result of the iterative feedback process, we obtained 281 standardized, representative mean CPUE values for a specific year, based on biocultural 282 consensus of green turtle captures.

Quantitative methods

Throughout the iterative process, we used descriptive statistics for exploratory data analysis and to identify outliers (Zar, 2014). We used NLR to describe CPUE trends over time and GLMs to identify significant predictor variables. We also integrated residual analysis to ensure that model assumptions were met and to evaluate goodness of fit and robustness. We ensured that residuals met the assumptions of zero mean, normal distribution, homoscedasticity, and independence $\left(\mathrm{e}_{\mathrm{i}} \sim \mathrm{N}\left(0, \sigma^{2}\right)\right.$ ) (Table 2; SI: Article S1) (Maunder \& Punt, 2004; Ritz \& Streibig, 
291 2008). In response to residual auto-correlation found during preliminary phases and exploratory

292 data analysis, as is common with time series data, we integrated residual correlation structures to

293 GLMs with residual auto-correlation during the final stages of standardization (Zuur, 2009). All

294 models reported in the Results meet the assumptions for robust residuals according to the criteria 295 described in Table 2 (see also SI: Article S1).

296 It should be noted that the statistical treatment is applied to the data series synthesized

297 from biocultural consensus. We used all available information to amass a year by year 298 remembrance of turtle captures by combining fishers' knowledge with that of key local 299 collaborators and community members. Thus, our synthesized data is not derived directly from

300 the individual, yearly recollections of specific fishers, but instead are the result of collectively 301 generated and corroborated knowledge. Likewise, statistical analyses were not conducted in 302 relation to the social groups themselves (aside from simple demographic description), but rather 303 to the quantified data synthesized from their collective knowledge, which included sea turtle 304 captures as well as descriptor variables, coefficients, and indices (Table 3). 
306 Phase 2: Recording, Synthesizing, and Quantifying LEK

307

308

309

310

311

312

313

314

315

316

317

318

319

320

321

322

323

324

325

326 327

\subsection{Documenting LEK}

M.M.E.C. and G.G.M. compiled ethnographic data in BLA over three field seasons (spring 2017, summer 2017, and spring 2018) and 57 working days. We obtained oral informed consent from all participants prior to the start of interviews, and recorded interviews in audio or video and took technical photographs when possible (SI: Article S1; Tables S2, S3) (International Society of Ethnobiology, 2006). We chose oral consent as it was not deemed culturally appropriate to ask participants to sign a consent document and because some participants were not comfortable with written language (International Society of Ethnobiology, 2006; Wedemeyer-Strombel et al., 2019). We conducted all interviews in Spanish - our primary language and that of the collaborators - and transcribed recorded interviews in digital format (.txt). We also compiled field journals in digital format (.txt), recording all observations in detail (SI: Article S1).

We validated ethnographic data through triangulation among (i) participants (e.g., data were independently corroborated and verified by multiple local collaborators), (ii) sources (e.g., documents, photographs, scientific literature, etc.), and/or (iii) methods (e.g, interviews, archive research, etc.). Once processed, we member-checked data for reliability by asking local collaborators from all groups if our themes or categories were locally relevant and congruent. We also asked local collaborators to identify data gaps, and inquired if overall accounts and processes were described in a manner that was realistic and accurate (Creswell \& Miller, 2000; Tengö et al., 2014). Prolonged engagement in the field allowed us to compare interview data with observations, and helped build trust so that participants were comfortable disclosing information, increasing reliability in responses (Bernard, 2011). 
We identified turtle fishers using a deliberate hierarchical sampling method (Bernard, 2011),

329 Turtle fishers are a small group of the oldest fishers in the community, between 55 and 85 years

330 of age $\left(\mathrm{N}_{\text {fishers }}=17\right)$. We interviewed $94 \%$ of turtle fishers, as one fisher chose not to participate.

331 All fishers in the population and sample were men. With this target group, we continuously

332 carried out participant observation, and conducted 17 semi-structured interviews (at least one per

333 person), along with 27 informal interviews. Within this target population, we identified a subset

334 of seven expert LEK holders, which we defined as turtle fishers recognized as experts by at least

335 two peers, and whose empirical and specialized knowledge can be used as a basis for inferences

336 and assessments about their surrounding environments and biota (cf. Bélisle et al., 2018). With

337 the group of expert LEK holders, along with the aforementioned methods, we conducted seven

338 in-depth interviews and one focus group discussion to gather specialized data (Tengö et al., 339 2014).

340 We identified key local collaborators $\left(n_{k l c}=7\right)$ through purposive and respondent-driven 341 sampling (Bernard, 2011). Key local collaborators were primarily older (> 63: 71\%) and 342 included women (43\%) and men (57\%). We continuously carried out participant observation

343 with this group, and conducted four in-depth interviews and 23 informal interviews. Topics

344 included: local history, economy, commerce, and foodways; marine and terrestrial ethnobiology

345 and conservation; and commercial and sport fishing, among others, which provided valuable

346 information for situating green turtle fishing within a broader socio-ecological context (Crandall

347 et al., 2018).

348 We selected local collaborators from the community at large $\left(\mathrm{n}_{\mathrm{cm}}=48\right)$ through a combination 349 of cluster sampling and self-selection (Bernard, 2011). They represented $\sim 8 \%$ of the population 350 of BLA and included women (42\%) and men (58\%). Ages ranged from 18-93, with young (18- 
351 39: 35\%), middle-aged (40-62: 37\%), and older (> 63: 28\%) participants. While we did not

352 inquire about income given local social taboos, local collaborators came from across all class

353 strata with schooling varying from individuals without formal schooling to graduate degree

354 holders. The group included both long-term residents (89\%) and short-term residents (11\%) such

355 as conservation workers and government employees. This diverse group provided a broad view

356 of perspectives and topics to complement and contextualize information from the target

357 population of turtle fishers. With this group, we continuously carried out participant observation 358 and conducted 72 informal interviews.

\subsection{Cataloguing LEK}

361 We processed and coded all field journals and interview transcriptions following a standardized

362 protocol. We used footnotes to separate observations from analysis, and for cross-referencing.

363 Cryptic indicators ensured local collaborators' anonymity (Bernard, 2011). We used cultural

364 material codes (Murdock et al., 2008) to categorize ethnographic data, with customized codes for

365 topics and themes specific to this research. We indexed text entries using hashtags (\#) to mark

366 relevant topics (e.g., \#fishing_gear), including ordinal codes (e.g., \#max_cpue; \#min_cpue) to

367 classify information for data-binning (SI: Article S1; see Table S4 for an example field journal

368 entry). Along with data compiled in the 2017 and 2018 field seasons, we coded and indexed

369 ethnographic materials collected since 2012 for integration into the qualitative database (SI:

370 Article S1; Tables S2, S3). Coding allowed us to break down qualitative data into analytical

371 variables and raw values (Strauss \& Corbin, 1994). Digital files allowed for analyzing large 
372 volumes of information by facilitating topic-specific searches, generating a corroborated,

373 systematized, and cross-referenced qualitative database (Bernard, 2011).

374

$375 \quad 2.3$ Synthesizing and Quantifying LEK

376 Qualitative analyses

377 We used qualitative textual analysis and discourse analysis to decipher the cultural, historical,

378 and political dimensions of the research topic; to identify potential sources of bias; and to

379 understand categories, processes, and connections (Crandall et al., 2018) (SI: Table S1). We

380 captured raw numerical data from interviews (SI: Article S1; Table S4), and used Quantitative

381 Textual Analysis tools in R 3.4 (wordcloud, tm, and SnowBallC packages) to identify themes and

382 patterns over large volumes of text, for a general overview (Bernard, 2011; R Core Team, 2019)

383 (SI: Article S1; Figures S2, S3). These themes helped us to identify potential descriptor

384 variables, indices, and topics for inquiry.

Quantifying LEK data

387 We defined explanatory variables for CPUE based on qualitative data (Table 3). We generated

388 initial indices for each variable based on the degree of detail and variation observed in interview

389 responses, and defined standardization and binning procedures (Figure 1).

390 We established four stages for the BLA green turtle fishery based on fishery landing statistics

391 and previous research (Early-Capistrán et al., 2018; Selgrath, Gergel \& Vincent, 2018): (1) 
392 commercial development; (2) commercial fishing (harpoons); (3) commercial fishing (nets); and

393 (4) collapse (Table 4). Qualitative data allowed for inferring that (i) fishing technology across the

394 fleet was similar within each stage; (ii) at all stages, fishers would make trips of varying duration

395 until reaching vessel capacity or exhausting food and water supplies; and, thus, (iii) CPUE could

396 be calculated based on the knowledge of fisheries stages, trip duration, fishing gear type,

397 displacement time, and vessel capacity (SI: Article S1). This framework allowed us to (i) bin

398 data and standardize variations in expertise and response terms, (ii) systematically complement

399 the knowledge of less experienced fishers with that of expert LEK holders, and (iii) account for

400 changes in fishing technology, effort, and efficiency over time (cf. Maunder \& Punt, 2004).

401 We generated digital (.txt) files to summarize categorical, ordinal, and numerical data for

402 each fisher (SI: Article S1; Table S5). Using social network analysis (Bernard, 2011), we

403 situated each fisher in relation to their fishing crew and extended family (Table 1). Ethnographic 404 and LEK data provided us with numerical anchor values and limits for variables during each 405 stage (Bélisle et al., 2018) (SI: Article S1).

406

\subsection{CPUE calculation and preliminary database generation}

408 To deal with variability, we used heuristic rules to make systematic inferences based on the

409 knowledge of expert LEK holders (Figure 3). This framework allowed us to calculate a central

410 tendency based on collectively-generated knowledge and biocultural consensus rather than

411 individual recollection, thus reducing individual cognitive bias (SI: Article S1). 
We converted captures reported by weight to number of turtles by dividing vessel

413 capacity by mode of turtle mass $(50 \mathrm{~kg})$ reported by fishers and corroborated with monitoring

414 data (Early-Capistrán et al., 2018) (SI: Article S1). While turtle size was highly variable and

415 likely declined in response to increasing fishing effort (Table 4), mixed juvenile/adult foraging

416 groups with a slight juvenile bias — such as BLA, where $\sim 56 \%$ of individuals are juveniles

417 (Seminoff et al., 2003) — are present in green turtle foraging habitats worldwide (Seminoff et al.,

418 2015). Thus, we consider our assumption regarding size distribution to be adequate given the

419 nature of the data (Table 4) (SI: Article S1).

\subsection{Preliminary data evaluation}

422

430

431

432

We estimated CPUE and descriptor variables through an iterative process. We stored data in .csv format and carried out all analyses in $R 3.4$ unless otherwise specified (R Core Team, 2019). We analyzed descriptive statistics to evaluate statistical robustness by checking data distribution, evaluating normality (Shapiro-Wilk p>0.05), and identifying outliers ( $\pm 2 \mathrm{SD})$ (Zar, 2014). Each CPUE data point was linked to a summary of qualitative and numerical data for a specific collaborator, and outlying data were contextualized and evaluated (Article S1, Table S5). Over the course of the iterative process, we discarded three CPUE values from fishers who (i) had less than one year of experience and (ii) were very young (10-13 years of age) when they captured turtles. During interviews, these fishers recognized that they had limited recollection of events and did not have the experience necessary to provide precise data. Statistical analysis confirmed that CPUE values provided by this group were outliers ( $\pm 2 \mathrm{SD})$. 
To evaluate CPUE trends, we converted values for the independent variable "year" to serial

434 form in all analyses. We used LABFit 7.2.49 to identify five preliminary models with best fit and

435 their respective starting values. We then ran NLR (nlstools, easynls, dplyr, car, and DescTools

436 packages; SI: Data and Code) to choose the model that best described the data, and evaluated

437 residuals (Table 2). We ran NLR at each round of the iterative process to (i) evaluate the general

438 behavior and performance of the data, (ii) identify outlier effects in residual analysis, and (iii)

439 evaluate if the process was robust to these effects (Baty et al., 2015; Ritz \& Streibig, 2008). An

440 exponential decay model consistently showed the best fit, with the form:

$$
\mathrm{Y} \sim \alpha \cdot \mathrm{e}^{(\beta \mathrm{x})}
$$

442 Where $Y$ is the response variable, CPUE; $\alpha$ is a constant (intercept); $\beta$ is an instantaneous rate of 443 change in the response variable (slope); and $x$ is the independent variable "year".

We used GLMs with a link function for Gaussian distributions to identify significant 445 predictor variables for CPUE (nlme, dplyr, car and DescTools packages), using log-transformed values if the CPUE distribution was non-normal (Zar, 2014). We ran backward-stepping models until we obtained a model with significant effects, a high percentage of explained deviance $\left(\mathrm{D}^{2}\right)$, a relatively low Akaike Information Criterion (AIC), and robust residuals (Table 2) (cf. Maunder \& Punt, 2004).

We ran a total of 36 NLR and 54 GLMs on five sequential working databases. The first three databases each corresponded to one round of the methodological cycle (Figure 1). With each round, the working databases were updated and superseded as we incorporated new data, variables, indices, analyses, and data cleaning processes (Figures 1, 3, and 4). The last two databases consisted of the final raw database -with LEK-derived CPUE values and 
455 heterogeneous variables for unit effort - and the standardized database with mean standardized

456 CPUE values for each year (SI: Data and Code). By integrating these analyses into the cyclical

457 process, we are confident that we adequately identified confounding variables and sources of

458 variation not attributable to changes in abundance (Hilborn \& Walters, 1992).

\subsection{Feedback integration}

461

We integrated model-fitting feedback by identifying which variables and indices required

462 further information or could be improved (Figure 4). We integrated feedback from community

463 members during subsequent visits to the field by sharing preliminary results and model outputs

464 with them through narrative description, and asking for collaborators' perspectives on validity

465 and consistency (Bélisle et al., 2018). Local collaborators also identified gaps and provided

466 further information (Huntington, 2000; Tengö et al., 2014). We then designed new questions

467 based on feedback and repeated these procedures with each variable (Figures 1 and 4).

We repeated the cyclical process of data gathering, synthesis, and quantification until

reaching topical saturation (similar instances were repeated and no additional data were found with which to develop new properties), thematic saturation (additional data did not produce new

471 emerging themes), data saturation (new data repeated what was expressed in previous data)

472 (Saunders et al., 2018), and until model fitting did not provide significant new information.

Time frames required to reach saturation are extensive, in the order of months or years.

474 Ethnographic fieldwork generally requires a year or more, given the extensive time required to 475 establish rapport, obtain working knowledge and understanding of the cultural context, and to be 
476 able to ask good questions and obtain good answers (Bernard, 2011). The interview process to

477 elicit the data presented in this article represented 57 working days over three field seasons 478 (spring 2017, summer 2017, and spring 2018). While it may seem a rather short timeframe, it 479 must be said that two of the authors, M.M.E.C. and G.G.M., have been conducting ethnographic 480 work in the community since the summer of 2012, making seven trips to the region with a mean 481 duration of 27 days, conducting a total of 378 interviews to date (SI: Tables S2, S3), and 482 maintaining contact and communication with community members between field seasons. Long483 term continuous interaction has allowed rapport for intelligible dialogue among researchers and 484 local community members in ways that enable elicitation of trustworthy data.

\section{Phase 3: Database Standardization and Validation}

\subsection{Raw CPUE Database Analysis}

The result of the methodological cycle was a final, LEK-derived CPUE database with heterogeneous variables for unit effort (raw database) (Figure 1). We carried out descriptive statistical analysis, NLR, and GLM analysis to evaluate the data and define standardization

491 procedures as described in Section 2.5.

\subsection{CPUE Database Standardization}

494 We standardized CPUE to (i) remove most of the variation not attributable to changes in

495 abundance by accounting for variables such as gears, fleet characteristics, fishers' experience, 
496 etc.; and (ii) generate CPUE values that could be compared over time (Hilborn \& Walters, 1992;

497 Maunder \& Punt, 2004). To choose predictor variables for standardization, we ran GLMs (nlme, 498 car, dplyr, and DescTools packages; SI: Data and Code) with log-transformed CPUE values and 499 a residual correlation structure based on an auto-regressive model of order $1(A R-1)$ structured by 500 the variable "year" (Zuur, 2009). We chose predictor variables for standardization using models 501 with significant effects, high percentage of explained deviance $\left(\mathrm{D}^{2}\right)$, relatively low Akaike 502 Information Criterion (AIC), and robust residuals (Table 2) (cf. Maunder \& Punt, 2004).

503 We generated detailed definitions of unit effort based on these analyses, in order to obtain 504 comparable values for turtles caught in one night. While fishers generally worked from dusk to 505 dawn, fishing times on any given night with either gear type could be variable. For modeling 506 purposes, we simplified values to $12 \mathrm{hr}$ blocks which reflect the vast majority of fishing effort 507 (SI: Article S1). For set-nets, we standardized unit effort to approximate ecological monitoring data (100 m 509 net soaking for $12 \mathrm{hr}$ ) (Koch, 2013; Seminoff et al., 2003):

$$
\mathrm{C}_{\mathrm{st}}=(\mathrm{t} \cdot \mathrm{R}) /\left(\mathrm{n}_{\mathrm{r}} \cdot \mathrm{R} \cdot 12 \mathrm{hr}\right)
$$

511 Where $C_{s t}$ is a standardized, representative value of CPUE during a specific year (turtles $12 \mathrm{hr}^{-1}$ );

$512 t$ is the number of turtles caught (turtles); and $n_{r}$ is the number of $100 \mathrm{~m}$ nets (no units). $R$ is net

513 length (in multiples of $100 \mathrm{~m})$, simplified to short $(\sim 100 \mathrm{~m}=\mathrm{R})$ or long $(\sim 200 \mathrm{~m}=2 \mathrm{R})$ (Table 3).

514 Soaking time is $12 \mathrm{hr}$. 
515 For harpoon captures, we assigned a skill coefficient ( $s$, percentage of success) (Table 3 ) to

516 each harpooner through social network analysis (Table 1), based on colleagues' assessment, such 517 that:

$$
\mathrm{C}_{\mathrm{st}}=\mathrm{t} \cdot \mathrm{s}^{-1} \cdot 12 \mathrm{hr}^{-1}
$$

The current ban on sea turtle fishing does not allow us to test for differences in susceptibility

to fishing gears. Harpoons and nets were not used simultaneously by any given fisher, and both

521 were used over a roughly equivalent number of hours per night. Thus, we considered these

522 values to be adequately standardized given the nature of the data. For years with multiple CPUE

523 values, we calculated the mean after standardization (SI: Article S1; Figures S4, S5).

\subsection{Evaluating statistical robustness}

526 We evaluated reliability through comparison with green turtle fishery statistics for BLA (annual 527 landings in tons, 1962-1982) (Márquez cited in Seminoff et al., 2008). CPUE and total landings 528 are both crude indicators of abundance, and comparative analyses have been used to assess the 529 accuracy of LEK-derived data (Damasio et al., 2015; Sáenz-Arroyo \& Revollo-Fernández, 530 2016). We compared the catch reduction rate and fitted an exponential decay model (QtiPlot 531 0.9.9.7) as an experimental process to evaluate trends in LEK-derived CPUE and annual landings

532 (SI: Article S1). We then standardized both datasets to z-scores to avoid effects from differences 533 in scales (SI: Figure S6) and used the Lin Concordance Correlation Coefficient (Lin CCC) to 534 assess agreement between paired values (DescTools package; SI: Data and Code) (Lin, 1989; 535 Altman \& Altman, 1999) (SI: Article S1; Figure S6). 


\section{Phase 4: Analysis of Standardized CPUE Data}

538 We performed descriptive statistical analysis and NLR on the standardized database, following 539 the procedures described in Section 2.5, to understand long-term abundance trends. We chose

540 NLR for final analyses because (i) analyses conducted in Phases 2 and 3 consistently showed an

541 exponential decay trend, and (ii) standardized CPUE data were not normally distributed

542 (Shapiro-Wilk, $\mathrm{p}=0.00334$ ), and NLR does not assume normally distributed data (Ritz \&

543 Streibig, 2008).

544 We ran a global sensitivity analysis using Markov-Chain Montecarlo (MCMC) methods in $R$

5453.4 (FME package; SI: Data and Code) to derive the data-dependent probability distribution of 546 the parameters. An MCMC samples from probability distributions to generate an ensemble of

547 parameter values that represent the parameter distribution (Soetaert \& Petzoldt, 2010). We ran an 548 MCMC with initial values from the model with best fit $(\alpha=18.911, \beta=-0.264)$, with non549 informative priors and 5000 iterations. We then estimated the effect of parameter uncertainty on 550 the model output and generated a posterior predictive distribution of the model by taking a 551 sample of the parameter probability function generated by the MCMC, running the model 100 552 times using a random draw of the parameters in the chain, and adding randomly distributed noise 553 to estimate measurement error (Soetaert \& Petzoldt, 2010). 
556 We generated a reliable, standardized green turtle fishery CPUE time-series from 1952-1982 by

557 synthesizing and quantifying LEK. Three GLMs fit selection criteria to be used for database

558 standardization, as described in Section 3.2 (Table 2). These models showed that year, fishing

559 gear type, vessel capacity, number of nets, net length, and fisher's experience were significant

560 predictor values for CPUE (Table 5). Given that each of these variables was incorporated into

561 CPUE calculation and standardization, we are confident that both our estimates and

562 standardization procedure were robust. Comparative analysis with fishery landing statistics

563 confirmed accuracy: standardized CPUE and annual landings showed catch declines of $95 \%$ and

$56496 \%$, respectively, and Lin CCC $(\rho=0.726)$ showed strong agreement (Figure 5).

565 All fishers consistently reported a declining trend during the fishery. This was consistent with

566 our models. The NLR with best fit indicated that green turtle abundance declined exponentially

567 through the four phases of the sea turtle fishery, likely driven by large-scale commercial 568 exploitation with increased fishing effort and efficiency from 1960 to $1980\left(\mathrm{R}^{2}=0.798\right)$ (Table 6;

569 Figure 6). Residual analysis suggested that the model was robust for the data (Table 2). MCMC

570 sensitivity analysis suggested that our model is robust over parameter intervals for $\alpha$ (15 to 35 )

571 and $\beta$ ( -0.12 to -0.06$)$. Parameter values for the model with best fit $(\alpha=24.112, \beta=-0.0929)$

572 occurred within these intervals (Figures S7). Furthermore, 94\% of our data points occurred

573 within the posterior predictive distribution, confirming that the model was a good fit for the data 574 (Figure S8).

575

576 Discussion

577 Integrative Methodological innovation

Peer] reviewing PDF | (2019:10:42113:2:1:NEW 11 Jun 2020) 
578 The importance of LEK data is increasingly recognized in conservation science (Lee et al., 2018;

579 Mason et al., 2019). However, there has been reticence in the scientific community regarding the

580 use of LEK due to concerns about accuracy, reliability, and potential biases caused by

581 differences in individual perception, memory, and recollection (O'Donnell, Pajaro \& Vincent,

582 2010; Daw, Robinson \& Graham, 2011). We are confident that such issues can be overcome

583 through innovative, transdisciplinary methodologies that incorporate trusted methods from the

584 social sciences and epistemological frameworks for incorporating multiple knowledge systems

585 (Reed, 2008; Tengö et al., 2014; St. John et al., 2014). Our work contributes to overcoming key

586 scientific challenges of using LEK as a consistent source of information by combining rigorous

587 approaches to LEK documentation, synthesis, quantification, and statistical analysis.

588 We have approached the issues of accuracy, reliability, and recollection bias through several 589 complementary processes. We used ethnography to document LEK, collecting verified, 590 corroborated, and detailed qualitative and numerical data. Ethnographic data allowed for

591 increased accuracy and reliability in comparison with data derived from structured questionnaire-

592 based surveys or interviews alone. This particularly relevant in scenarios of high socio-

593 environmental and biological complexity where multiple variables can affect or bias estimates of

594 species abundance (Crandall et al., 2018; St. John et al., 2014). Ethnographic data also allowed

595 us to understand the trajectory of human impacts on green turtle abundance in detail. This 596 approach allowed us to describe, quantify, and integrate the social, economic, and technological

597 processes that affected the green turtle fishery into our estimates and indices, (e.g., changes in

598 fishing gear and displacement capacities, commercial demand, spatial dynamics, etc.). Thus, we

599 incorporated detailed knowledge of the nature and evolution of the green turtle fishery into our

600 models. We reduced cognitive bias and recollection bias by estimating CPUE on the basis of 
601 biocultural consensus from multiple, nested knowledge systems rather than direct individual 602 recollection. Finally, we integrated statistical analysis and feedback throughout all phases of our 603 methodology to assure statistical robustness.

604 The strong concurrence of our LEK-derived CPUE estimates with fishery landing data for 605 the historical fishery years (1962-1982) helps confirm the accuracy of LEK as a source of 606 information for understanding population trends in the recent past (Damasio et al., 2015; Sáenz607 Arroyo \& Revollo-Fernández, 2016). Robust model-fitting and sensitivity analyses confirmed 608 statistical reliability. Thus, we are confident that our methods provide practical approaches to the 609 scientific challenges of using LEK in conjunction with ecological modeling through detailed 610 LEK documentation, biocultural consensus, and continuous statistical analysis and feedback.

611 Spatial dynamics present an interesting area of opportunity for future research building upon 612 our methods. The development of sound approaches to management and conservation requires 613 understanding fishing effort over both space and time (Anticamara et al., 2011; Selgrath et al., 614 2018). We approached spatial variability through proxies (e.g., propulsion and trip duration, 615 Tables 3 and 4) due to the very high variability and complexity of spatial dynamics over time. 616 Given that our primary focus was on temporal trends in CPUE, these proxies provided a simple 617 index to account for spatial effort (Hilborn \& Walters, 1992; Walters, 2003). LEK-based studies 618 of spatial dynamics have primarily been conducted with present-day, data-poor fisheries (cf. 619 Moore et al., 2010; Moreno-Báez et al., 2010; Selgrath et al., 2018). In future, the application of 620 our methods for detailed reconstruction of the spatial dynamics of the green turtle fishery 621 through LEK could have important potential for uncovering historical green turtle spatial 622 distribution and habitat use, and understanding changes in spatial dynamics over broad temporal 623 scales. 
624 We recognize that LEK data is epistemologically distinct from technical data, and have

625 aimed to bridge epistemological gaps and produce a synergistic integration of LEK and scientific

626 methods (cf. Brook \& McLachlan, 2005; Tengö et al., 2014). As scientists, we recognize that our

627 research is value-laden and that the inevitable differences between LEK and technical data are

628 more often reflections of epistemological differences or methods of collection than inherent

629 unreliability (Brook \& McLachlan, 2005). LEK research requires trust-based collaboration

630 between researchers and communities, a process that can necessitate years of commitment

631 (Brook \& McLachlan, 2005). In such contexts, when researchers can elicit and corroborate

632 qualitative data derived from empirically-lived situations (Palmer \& Wadley, 2007), synthesize

633 and quantify this data, and submit quantified data to rigorous mathematical analysis, they can

634 assure that LEK-derived estimates are accurate and statistically reliable. Such information is of

635 crucial importance for conservation and management, particularly in scenarios where there is a

636 need for understanding long-term trends; where technical data are scarce or unavailable; or

637 where species are impacted by illegal, unregulated or undocumented exploitation (Duffy et al.,

638 2016; Pauly, 1995; Sáenz-Arroyo \& Revollo-Fernández, 2016). Concomitantly, the integration

639 of LEK and scientific knowledge offers the possibilities of incorporating and empowering local

640 conservation processes with peoples previously seen as deleterious agents for those same

641 environments and species of which they hold a vast amount of LEK (cf. Berkes et al., 2005).

642 Lastly, the use of LEK provides comprehensive understanding of complex and dynamic socio-

643 ecological processes while facilitating the creation and implementation of culturally appropriate

644 local solutions to environmental problems (cf. Reed, 2008; Brown, 2010).

645

646 Understanding East Pacific green turtle population trends

Peer] reviewing PDF | (2019:10:42113:2:1:NEW 11 Jun 2020) 
647 Our LEK-derived CPUE data provide a baseline abundance of green turtles before large-scale 648 commercial exploitation at a key feeding area in the Gulf of California, and describe population 649 trends prior to ecological monitoring which are essential for establishing conservation and 650 management goals (McClenachan et al., 2016; Seminoff et al., 2003). Our approach provides a 651 historical reference point for the Bahía de los Ángeles foraging population and enables us to 652 better understand contemporary datasets and current population status in the area (Seminoff et 653 al., 2008). Our results suggest that fishery-derived mortality exceeded replacement via 654 reproduction or immigration rates into the feeding areas (Chaloupka \& Musick, 1996). 655 Furthermore, although fishing effort and efficiency increased over time, previous CPUE could 656 not be maintained due to the overall decline in green turtle abundance (Hilborn \& Walters, 657 1992). We are confident that CPUE values in the 1950s can be considered an adequate historical 658 baseline abundance level, based on previous research which identified the early 1960s as a 659 period when human impacts precipitated a major decline in green turtle abundance in the Gulf of 660 California (Early-Capistrán et al., 2018).

661 Future research that pairs LEK-derived estimates with contemporary in-water monitoring and 662 nesting data can provide fundamental insights for conservation status evaluations such as those 663 conducted under the auspices of the IUCN Red List (Mazaris et al., 2017; Seminoff \& Shanker, 664 2008). Such long-term perspectives are generally not attainable via scientific monitoring efforts 665 alone, especially considering that although sea turtles have been exploited worldwide for 666 centuries or millennia, even the longest tenured sea turtle monitoring programs only started the 667 1960s (Balazs \& Chaloupka, 2004; Bjorndal, Bolten \& Chaloupka, 2005; Chaloupka \& Limpus, 668 2001; Márquez, 1996). 
In the case of BLA, existing baseline data from 1995 correspond to a decimated population,

670 and would thus be prone to over-estimating the degree of initial recovery observed from the early

671 2000s onward (Delgado-Trejo, 2016; Pauly, 1995; Seminoff et al., 2015). Currently, scientific

672 surveys are conducted monthly using CPUE as an index. Catch effort is variable within specific

673 parameters, using 100-200 m set-nets and 12-24 hr soak times (Koch, 2013; Seminoff et al.,

674 2008). In future, our standardized LEK-derived CPUE estimates can be integrated with

675 standardized monitoring data to provide a long-term view of green turtle abundance at this index

676 feeding area. Integration of past trends with modern-day survey data is crucial for evaluating the

677 overall conservation status of the East Pacific green turtle with references to baseline abundance

678 levels prior to large-scale commercial exploitation (Broderick et al., 2006; Seminoff \& Shanker, 679 2008; Wildermann et al., 2018).

680

\section{Conclusions}

682 Our reconstruction of baseline conditions revealed an exponential decline in green turtle

683 abundance between 1960 and 1980 at Bahía de los Ángeles, one of the most important and

684 productive green turtle commercial fishing areas in the eastern Pacific Ocean (Caldwell, 1963;

685 Early-Capistrán et al., 2018). As scientific monitoring began only in 1995 after population

686 collapse, no pre-exploitation baseline data were available to evaluate current abundance and

687 conservation status (Seminoff et al., 2008). Our LEK-derived data can now provide historical

688 context and a reliable baseline abundance estimate for this green turtle population. We are

689 confident that future studies integrating our LEK-derived estimates with current scientific

690 monitoring data from both foraging habitats and nesting beaches will yield a holistic, long-term 
691 perspective of green turtle abundance, conservation, and population dynamics in the eastern 692 Pacific.

693 Beyond reconstructing green turtle abundance, our methodology may be exported to parallel 694 cases dealing with the conservation and monitoring of other long-lived species that are fished as 695 it can unravel complex phenomena by combining LEK and ecological modeling. We provide a 696 framework to overcome the challenges of documenting and quantifying LEK, and bridge 697 practical and epistemological gaps (Mistry \& Berardi, 2016; Mukherjee et al., 2018). This 698 approach provides a way to deal with variation in individual memory using corroborated data 699 and collectively produced knowledge, to simplify and manage large volumes of qualitative 700 information, and to translate qualitative data into a format compatible with ecological modeling 701 (Bélisle et al., 2018).

702

We recognize that of LEK and derived population abundance estimates are technically and 703 epistemologically distinct from data obtained under experimental conditions. Nevertheless, they can provide a robust description of significant inflection points in abundance trends that would be less-resolved if analyses were limited to scantly-available technical data (Pauly, 1995; SáenzArroyo \& Revollo-Fernández, 2016). LEK-based and integrative approaches can provide longterm information where scientific monitoring data are scarce or unavailable, and contribute to collaborative knowledge production (Barrios-Garrido et al., 2018; Lee et al., 2018; Mistry \& Berardi, 2016). While our methods are most readily adapted to marine fauna such as marine mammals, reptiles, teleost fish, and long-lived invertebrates, this approach can also be modified

711 and applied to terrestrial and freshwater biota. We trust that future research that rigorously

712 integrates social and ecological science can help address challenges for conservation and 
713 management in the context of global change and biodiversity loss (Mukherjee et al., 2018;

714 Sutherland et al., 2018).

715

716 Acknowledgements

717 We thank the community of Bahía de los Ángeles for their trust and partnership. We thank the

718 Graduate Program in Ocean Sciences and Limnology at the National Autonomous University of

719 Mexico (PCMyL-UNAM), where this research was conducted as part of M.M.E.C.'s doctoral

720 studies. While conducting this research, M.M.E.C. received an academic grant from the Mexican

721 National Council for Science and Technology-CONACYT (contract number: 289695). We are

722 extremely grateful for the support provided by Centro de Investigación Científica y Educación

723 Superior de Ensenada through the Sub-estación Bahía de los Ángeles (SEBLA) and Laboratory

724 of Mathematical Ecology; Comisión Nacional de Áreas Naturales Protegidas; A.N.P.F.F. Islas

725 del Golfo de California; and Grupo Tortuguero de las Californias A.C.. We are grateful for

726 support from J. Candela-Pérez, O. Flores-Uzeta, I. Fuentes, J. Medina-Rodríguez, V. Moreno, S.

727 Aztorga, and H. Salinas. We thank an anonymous reviewer and Lynn Lee for their thoughtful

728 reviews that greatly improved the quality of this manuscript.

729

730

References

731 Ainsworth CH. 2011. Quantifying Species Abundance Trends in the Northern Gulf of California 732 Using Local Ecological Knowledge. Marine and Coastal Fisheries 3:190-218. DOI: $10.1080 / 19425120.2010 .549047$. 
734 Altman DG, Altman E. 1999. Practical Statistics for Medical Research. London: Chapman and 735 Hall/CRC.

736 737

738

Anticamara JA, Watson R, Gelchu A, Pauly D. 2011. Global fishing effort (1950-2010): Trends, gaps, and implications. Fisheries Research 107:131-136. DOI: 10.1016/j.fishres.2010.10.016.

Balazs GH, Chaloupka M. 2004. Thirty-year recovery trend in the once depleted Hawaiian green sea turtle stock. Biological Conservation 117:491-498. DOI: 10.1016/j.biocon.2003.08.008.

Bao K, Drew J. 2017. Traditional ecological knowledge, shifting baselines, and conservation of Fijian molluscs. Pacific Conservation Biology 23:81. DOI: 10.1071/PC16016.

Barrios-Garrido H, Palmar J, Wildermann N, Izales DR-C, Diedrich A, Hamann M. 2018. Marine Turtle Presence in the Traditional Pharmacopoeia, Cosmovision, and Beliefs of Wayuú Indigenous People. Chelonian Conservation and Biology 17:177. DOI: 10.2744/CCB-1276.1.

Baty F, Ritz C, Charles S, Brutsche M, Flandrois J-P, Delignette-Muller M-L. 2015. A Toolbox for Nonlinear Regression in $R$ : The Package nlstools. Journal of Statistical Software 66. DOI: 10.18637 jss.v066.i05.

Beaudreau AH, Levin PS. 2014. Advancing the use of local ecological knowledge for assessing data-poor species in coastal ecosystems. Ecological Applications 24:244-256.

Bélisle AC, Asselin H, LeBlanc P, Gauthier S. 2018. Local knowledge in ecological modeling. Ecology and Society: 11.

Berkes F, Bankes N, Marschke M, Armitage D, Clark D. 2005. Cross-scale Institutions and Building Resilience in the Canadian North. In: Berkes F, Huebert H, Fast M, Manseau M, 
Diduck A eds. Breaking ice: renewable resource and ocean management in the Canadian North. Calgary, Alberta, Canada: University of Calgary Press, 225-247.

Bernard HR. 2011. Research Methods in Anthropology: Qualitative and Quantitative Approaches. New York: AltaMira Press.

761 Bjorndal KA, Bolten AB, Chaloupka MY. 2005. Evaluating trends in abundance of immature green turtles, Chelonia mydas, in the greater Caribbean. Ecological Applications 15:304-

Broderick AC, Frauenstein R, Glen F, Hays GC, Jackson AL, Pelembe T, Ruxton GD, Godley BJ. 2006. Are green turtles globally endangered? Global Ecology and Biogeography 15:21-26. DOI: 10.1111/j.1466-822X.2006.00195.x.

Brook RK, McLachlan SM. 2005. On Using Expert-Based Science to “Test” Local Ecological 768 Knowledge. Ecology and Society 10:resp3. DOI: 10.5751/ES-01478-1002r03.

Brown VA. 2010. Collective Inquiry and Its Wicked Problems. In: Brown VA, Harris JA, 770 Russell JY eds. Tackling wicked problems through the transdisciplinary imagination. London; Washington, DC: Earthscan, 61-81.

Caldwell DK. 1963. The sea turtle fishery of Baja California, Mexico. California Fish and Game 49:140-151.

Castro FR de, Stutz-Reis S, Reis SS, Nakano-Oliveira E, Andriolo A. 2014. Fishermen's 775 perception of Neotropical otters (Lontra longicaudis) and their attacks on artisanal fixed fence traps: The case of caiçara communities. Ocean \& Coastal Management 92:19-27. DOI: 10.1016/j.ocecoaman.2014.01.008.

Chaloupka M, Bjorndal KA, Balazs GH, Bolten AB, Ehrhart LM, Limpus CJ, Suganuma HS, Troëng S, Yamaguchi M. 2008. Encouraging outlook for recovery of a once severely 
exploited marine megaherbivore. Global Ecology and Biogeography 17:297-304. DOI:

781 10.1111/j.1466-8238.2007.00367.x.

782 Chaloupka M, Limpus C. 2001. Trends in the abundance of sea turtles resident in southern Great 783 Barrier Reef waters. Biological Conservation 102:235-249. DOI: 10.1016/S0006-

Chaloupka M, Musick JA. 1996. Age, Growth, and Population Dynamics. In: Lutz PL, Musick 786 JA, Wyneken J eds. The biology of sea turtles. CRC Marine science series. Boca Raton, Fla: CRC Press, 233-276.

Crandall SG, Ohayon JL, de Wit LA, Hammond JE, Melanson KL, Moritsch MM, Davenport R, Ruiz D, Keitt B, Holmes ND, Packard HG, Bury J, Gilbert GS, Parker IM. 2018. Best practices: social research methods to inform biological conservation. Australasian Journal of Environmental Management 25:6-23. DOI: 10.1080/14486563.2017.1420499.

Creswell JW, Miller DL. 2000. Determining Validity in Qualitative Inquiry. Theory Into 793 Practice 39:124-130. DOI: 10.1207/s15430421tip3903_2.

Damasio L de MA, Lopes PFM, Guariento RD, Carvalho AR. 2015. Matching Fishers' 795 Knowledge and Landing Data to Overcome Data Missing in Small-Scale Fisheries. PLOS 796 ONE 10:e0133122. DOI: 10.1371/journal.pone.0133122.

Daw TM, Robinson J, Graham NAJ. 2011. Perceptions of trends in Seychelles artisanal trap 798 fisheries: comparing catch monitoring, underwater visual census and fishers' knowledge. Environmental Conservation 38:75-88. DOI: 10.1017/S0376892910000901.

Delgado-Trejo C. 2016. Recovery of the Black Sea Turtle in Michoacan, Mexico: Final Report to 801 the U.S. Fish and Wildlife Service. Morelia, Mexico: U.S. Fish and Wildlife Service and Universidad Michoacana San Nicolás Hidalgo. 
803 Diario Oficial de la Federación. 1990. Acuerdo por el que se establece veda para las especies y 804 subespecies de tortuga marina en aguas de jurisdicción Federal del Golfo de México y 805 Mar Caribe, así como en las del Océano Pacífico, incluyendo el Golfo de California.

806 Drury R, Homewood K, Randall S. 2011. Less is more: the potential of qualitative approaches in 807 conservation research: Qualitative approaches in conservation research. Animal 808 Conservation 14:18-24. DOI: 10.1111/j.1469-1795.2010.00375.x.

Duffy R, St John FAV, Büscher B, Brockington D. 2016. Toward a new understanding of the links between poverty and illegal wildlife hunting: Poverty and Illegal Wildlife Hunting. Conservation Biology 30:14-22. DOI: 10.1111/cobi.12622.

Early-Capistrán MM. 2014. Análisis diacrónico de la explotación, abundancia y talla de 814 Chelonia mydas en la península de Baja California, 12,000 A.P.-2012. M.Sc. Thesis. Mexico City: Universidad Nacional Autónoma de México. Koch V. 2018. Reconstructing 290 years of a data-poor fishery through ethnographic and archival research: The East Pacific green turtle (Chelonia mydas) in Baja California, Mexico. Fish and Fisheries 19:57-77. DOI: 10.1111/faf.12236.

Godley BJ, Barbosa C, Bruford M, Broderick AC, Catry P, Coyne MS, Formia A, Hays GC, Witt MJ. 2010. Unravelling migratory connectivity in marine turtles using multiple 824

Hilborn R, Walters CJ. 1992. Quantitative Fisheries Stock Assessment: Choice, Dynamics and Uncertainty. Dordrecht: Springer Science+Business Media. 
825 Huntington HP. 2000. Using traditional ecological knowledge in science: methods and $826 \quad$ applications. Ecological applications 10:1270-1274.

827 International Society of Ethnobiology. 2006. ISE Code of Ethics (with 2008 additions).

828 IUCN. 2019. The IUCN Red List of Threatened Species. Available at 829 https://www.iucnredlist.org/en (accessed July 10, 2019).

830 Jackson JB, Kirby MX, Berger WH, Bjorndal KA, Botsford LW, Bourque BJ, Bradbury RH, 831 Cooke R, Erlandson J, Estes JA. 2001. Historical overfishing and the recent collapse of $832 \quad$ coastal ecosystems. Science 293:629-637.

833 Johannes RE. 1981. Words of the Lagoon: Fishing and Marine Lore in the Palau District of 834 Micronesia. Berkeley: University of California Press.

835 Koch V. 2013. 12 años de monitoreo de la tortuga negra (Chelonia mydas) en zonas de 836 alimentación y crianza en el Noroeste de México. La Paz, B.C.S., Mexico: Grupo 837 Tortuguero de las Californias A.C.

838 Lee LC, Thorley J, Watson J, Reid M, Salomon AK. 2018. Diverse knowledge systems reveal social-ecological dynamics that inform species conservation status. Conservation Letters:e12613. DOI: 10.1111/conl.12613.

841 Lin LI-K. 1989. A Concordance Correlation Coefficient to Evaluate Reproducibility. Biometrics 45:255. DOI: $10.2307 / 2532051$.

843 López-Castro M, Koch V, Mariscal-Loza A, Nichols W. 2010. Long-term monitoring of black turtles Chelonia mydas at coastal foraging areas off the Baja California Peninsula. Endangered Species Research 11:35-45. DOI: 10.3354/esr00264.

846 Márquez R. 1996. Las tortugas marinas y nuestro tiempo. Mexico City: Fondo de Cultura Económica. 
848 Mason JG, Alfaro-Shigueto J, Mangel JC, Brodie S, Bograd SJ, Crowder LB, Hazen EL. 2019.

849 Convergence of fishers' knowledge with a species distribution model in a Peruvian shark 850 fishery. Conservation Science and Practice 1:e13. DOI: $10.1111 / \mathrm{csp} 2.13$.

851 Maunder MN, Punt AE. 2004. Standardizing catch and effort data: a review of recent 852 approaches. Fisheries Research 70:141-159. DOI: 10.1016/j.fishres.2004.08.002.

853 Mazaris AD, Schofield G, Gkazinou C, Almpanidou V, Hays GC. 2017. Global sea turtle 854 conservation successes. Science Advances 3:e1600730. DOI: 10.1126/sciadv.1600730.

855 McClenachan L, Cooper AB, Hardt M, McKenzie M, Drew JA. 2016. Conservation implications 856 of omitting historical data sources: response to Baisre: Conservation and Historical Data. Conservation Biology 30:226-227. DOI: 10.1111/cobi.12638.

858 Mistry J, Berardi A. 2016. Bridging indigenous and scientific knowledge. Science 352.

859 Moller H, Berkes F, Lyver PO, Kislalioglu M. 2004. Combining Science and Traditional 860 Ecological Knowledge: Monitoring Populations for Co-Management. Ecology and $861 \quad$ Society 9. DOI: 10.5751/ES-00675-090302.

862 Moon K, Blackman DA, Adams VM, Colvin RM, Davila F, Evans MC, Januchowski-Hartley 863 SR, Bennett NJ, Dickinson H, Sandbrook C, Sherren K, St. John FAV, van Kerkhoff L, 864 Wyborn C. 2019. Expanding the role of social science in conservation through an 865 engagement with philosophy, methodology, and methods. Methods in Ecology and 866 Evolution. DOI: 10.1111/2041-210X.13126.

867 Moore JE, Cox TM, Lewison RL, Read AJ, Bjorkland R, McDonald SL, Crowder LB, Aruna E, 868 Ayissi I, Espeut P, Joynson-Hicks C, Pilcher N, Poonian CNS, Solarin B, Kiszka J. 2010. An interview-based approach to assess marine mammal and sea turtle captures in 
artisanal fisheries. Biological Conservation 143:795-805. DOI:

872 Moreno-Báez M, Orr BJ, Cudney-Bueno R, Shaw WW. 2010. Using fishers' local knowledge to aid management at regional scales: spatial distribution of small-scale fisheries in the northern Gulf of California, Mexico. Bulletin of Marine Science 86:339-353.

875 Mukherjee N, Zabala A, Huge J, Nyumba TO, Adem Esmail B, Sutherland WJ. 2018. 876 Comparison of techniques for eliciting views and judgements in decision-making. Methods in Ecology and Evolution 9:54-63. DOI: 10.1111/2041-210X.12940.

878 Murdock GP, Clellan SF, Hudson AE, Kennedy R, Simmons LW, Whiting JWM. 2008. Outline of Cultural Materials. 6th revised edition with Modifications. New Haven: Human Relations Area Files.

881 Narchi NE, Cornier S, Canu DM, Aguilar-Rosas LE, Bender MG, Jacquelin C, Thiba M, Moura GGM, de Wit R. 2014. Marine ethnobiology a rather neglected area, which can provide an important contribution to ocean and coastal management. Ocean \& Coastal Management 89:117-126. DOI: 10.1016/j.ocecoaman.2013.09.014.

O’Donnell KP, Pajaro MG, Vincent ACJ. 2010. How does the accuracy of fisher knowledge affect seahorse conservation status?: Fisher recall accuracy affects conservation status. Animal Conservation 13:526-533. DOI: 10.1111/j.1469-1795.2010.00377.x.

Palmer CT, Wadley RL. 2007. Local Environmental Knowledge, Talk, and Skepticism: Using 'LES' to Distinguish 'LEK' from 'LET' in Newfoundland. Human Ecology 35:749-760. DOI: $10.1007 / \mathrm{s} 10745-006-9108-\mathrm{z}$.

Pauly D. 1995. Anecdotes and the shifting baseline syndrome of fisheries. Trends in Ecology \& Evolution 10:430. 
893 R Core Team. 2019. A language and environment for statistical computing. Vienna, Austria.: R $894 \quad$ Foundation for Statistical Computing.

895 Reed MS. 2008. Stakeholder participation for environmental management: A literature review. 896 Biological Conservation 141:2417-2431. DOI: 10.1016/j.biocon.2008.07.014.

897 Ritz C, Streibig JC. 2008. Nonlinear regression with R. New York: Springer.

898 Sáenz-Arroyo A, Revollo-Fernández D. 2016. Local ecological knowledge concurs with fishing 899 statistics: An example from the abalone fishery in Baja California, Mexico. Marine 900 Policy 71:217-221. DOI: 10.1016/j.marpol.2016.06.006.

901 Sáenz-Arroyo A, Roberts CM, Torre J, Cariño-Olvera M. 2005. Using fishers' anecdotes, 902 naturalists' observations and grey literature to reassess marine species at risk: the case of 903 the Gulf grouper in the Gulf of California, Mexico. Fish and Fisheries 6:121-133.

904 Saunders B, Sim J, Kingstone T, Baker S, Waterfield J, Bartlam B, Burroughs H, Jinks C. 2018. 905 906 Saturation in qualitative research: exploring its conceptualization and operationalization. Quality \& Quantity 52:1893-1907. DOI: 10.1007/s11135-017-0574-8.

Selgrath JC, Gergel SE, Vincent ACJ. 2018. Shifting gears: Diversification, intensification, and 908 effort increases in small-scale fisheries (1950-2010). PLOS ONE 13:e0190232. DOI: 10.1371/journal.pone.0190232.

910 Selgrath JC, Gergel SE, Vincent ACJ, Handling editor: Ruth Thurstan. 2018. Incorporating 911 spatial dynamics greatly increases estimates of long-term fishing effort: a participatory

912 mapping approach. ICES Journal of Marine Science 75:210-220. DOI: 10.1093/icesjms/fsx108. 
914 SEMARNAT. 2010. NORMA Oficial Mexicana NOM-059-SEMARNAT-2010, Protección 915 ambiental-Especies nativas de México de flora y fauna silvestres-Categorías de riesgo y 916 especificaciones para su inclusión, exclusión o cambio-Lista de especies en riesgo.

917 Seminoff JA, Allen CD, Balazs G, Dutton PH, Eguchi T, Haas HL, Hargrove S, Jensen M, 918 Klemm DL, Lauritsen AM, MacPherson SL, Opay P, Possardt EE, Pultz S, Seney E, Van 919 Houtan KS, Waples RS. 2015. Status Review of the Green Turtle (Chelonia mydas) 920 Under the Endangered Species Act. San Diego, USA: NOAA.

921 Seminoff JA, Jones TT, Resendiz A, Nichols WJ, Chaloupka MY. 2003. Monitoring green 922 turtles (Chelonia mydas) at a coastal foraging area in Baja California, Mexico: multiple 925 926 indices to describe population status. Journal of the Marine Biological Association of the UK 83:1355-1362.

Seminoff JA, Resendiz A, Nichols WJ. 2002. Home range of green turtles Chelonia mydas at a coastal foraging area in the Gulf of California, Mexico. Marine Ecology Progress Series 242:253-265.

Seminoff JA, Reséndiz-Hidalgo A, Jiménez de Reséndiz B, Nichols WJ, Todd-Jones T. 2008. Tortugas marinas. In: Danemann G, Ezcurra E eds. Bahía de los Ángeles: recursos naturales y comunidad: línea base 2007. Tlalpan, México D.F.; San Diego, Calif.: Secretaría de Medio Ambiente y Recursos Naturales; San Diego Natural History 932 Museum, 457-494.

Seminoff JA, Shanker K. 2008. Marine turtles and IUCN Red Listing: A review of the process, 935 the pitfalls, and novel assessment approaches. Journal of Experimental Marine Biology and Ecology 356:52-68. DOI: 10.1016/j.jembe.2007.12.007. 
936 Senko J, Megill W, Brooks L, Templeton R, Koch V. 2019. Developing low-cost tags: assessing 937 the ecological impacts of tethered tag technology on host species. Endangered Species $938 \quad$ Research 39:255-268. DOI: 10.3354/esr00967.

939 Soetaert K, Petzoldt T. 2010. Inverse Modelling, Sensitivity and Monte Carlo Analysis in $R$ $940 \quad$ Using Package FME. Journal of Statistical Software 33. DOI: 10.18637/jss.v033.i03.

941 St. John FAV, Keane AM, Jones JPG, Milner-Gulland EJ. 2014. FORUM: Robust study design 942 is as important on the social as it is on the ecological side of applied ecological research. Journal of Applied Ecology 51:1479-1485. DOI: 10.1111/1365-2664.12352.

944

945

946

947

948

949

950

951

952

953 954

955

956

957

Strauss A, Corbin J. 1994. Grounded Theory Methodology: An Overview. In: Denzin, Norma K., Lincoln YS eds. Handbook of qualitative research. Thousand Oaks, CA, US: Sage Publications, 273-285.

Sutherland WJ, Dicks LV, Everard M, Geneletti D. 2018. Qualitative methods for ecologists and conservation scientists. Methods in Ecology and Evolution 9:7-9. DOI: 10.1111/2041210X.12956.

Tengö M, Brondizio ES, Elmqvist T, Malmer P, Spierenburg M. 2014. Connecting Diverse Knowledge Systems for Enhanced Ecosystem Governance: The Multiple Evidence Base Approach. AMBIO 43:579-591. DOI: 10.1007/s13280-014-0501-3.

Walters C. 2003. Folly and fantasy in the analysis of spatial catch rate data. Canadian Journal of Fisheries and Aquatic Sciences 60:1433-1436. DOI: 10.1139/f03-152.

Wedemeyer-Strombel KR, Peterson MJ, Sanchez RN, Chavarría S, Valle M, Altamirano E, Gadea V, Sowards SK, Tweedie CE, Liles MJ. 2019. Engaging Fishers' Ecological Knowledge for Endangered Species Conservation: Four Advantages to Emphasizing 

10.3389/fcomm.2019.00030.

960 Wildermann N, Gredzens C, Avens L, Barrios-Garrido H, Bell I, Blumenthal J, Bolten A, Braun

961

962

963

964

965

966

967

968

969

970

971

972

973

974

McNeill J, Casale P, Di Domenico M, Domit C, Epperly S, Godfrey M, Godley B, González-Carman V, Hamann M, Hart K, Ishihara T, Mansfield K, Metz T, Miller J, Pilcher N, Read M, Sasso C, Seminoff J, Seney E, Willard A, Tomás J, Vélez-Rubio G, Ware M, Williams J, Wyneken J, Fuentes M. 2018. Informing research priorities for immature sea turtles through expert elicitation. Endangered Species Research 37:55-76. DOI: $10.3354 /$ esr00916.

Young JC, Rose DC, Mumby HS, Benitez-Capistros F, Derrick CJ, Finch T, Garcia C, Home C, Marwaha E, Morgans C, Parkinson S, Shah J, Wilson KA, Mukherjee N. 2018. A methodological guide to using and reporting on interviews in conservation science research. Methods in Ecology and Evolution 9:10-19. DOI: 10.1111/2041-210X.12828.

Zar JH. 2014. Biostatistical Analysis. London: Pearson.

Zuur AF (ed.). 2009. Mixed effects models and extensions in ecology with R. New York, NY: Springer. 


\section{Box 1(on next page)}

Primary topic areas in interview guides 
1

2

3

4

5

6

7

8

\section{Biographical data and career history}

Year of birth

Years in the community

Years as a fisher

Years in the green turtle fishery

Crew members and fishing merchants with whom they worked

\section{Sea turtle consumption and commerce}

Domestic sea turtle consumption dynamics (before 1990 ban)

Market dynamics for sea turtle sale (how, where, and how often turtles were shipped)

Commercial dynamics (how turtles were sold, prices, working relationships, etc.)

\section{Sea turtle catches and sizes}

Maximum and minimum catches

Frequency of aggregations and large catches

Average catches

Perceived changes in abundance

Size distribution (maximum and mode sizes, frequency of catching large turtles)

Sea turtle ethnobiology (effects of seasonality, tides, green turtle behavior, etc.)

\section{Spatial distribution of fishing}

Frequently used fishing grounds

Hot-spot and aggregation dynamics

Changes in use of fishing grounds across time

Distances and travel times to fishing grounds

\section{Fishing effort and technology}

Use and efficiency of different gear types/gear designs

Use of different vessels

Use of different propulsion systems 


\section{Table $\mathbf{1}$ (on next page)}

Methods used for data collection during ethnographic field work 


\begin{tabular}{ll} 
Method & Definition \\
\hline $\begin{array}{l}\text { Participant } \\
\text { observation }\end{array}$ & $\begin{array}{l}\text { Studying a social group } \\
\text { through a combination of direct } \\
\text { observation and immersion in } \\
\text { group activities as an active } \\
\text { participant }\end{array}$
\end{tabular}

Informal interviews

Interviews without structure or control, often conversations held during the course of fieldwork

Semi-structured interviews

In-depth
interviews

In-depth interviews about life stories, experiences, and eyewitness accounts

Aimed at obtaining detailed understanding of the topic of interest. Participants can communicate more freely and provide more detailed descriptions than with semistructured interviews.

Moderated discussions with small groups (<10 people) on a particular topic

Oral histories

Contributors draw maps, Participatory mapping locate key places on maps, or locate key sites together with researchers

Social network analysis

Identifying the structure of social relations

Analysis of communicative content and structure focused on how meaning is constructed and how power functions in a society
Example of applications

Participating in and documenting sport-fishing trips led by former green turtle fishers

Conversations with fishers or their family members recorded in written notes

Contributors were interviewed using an interview guide with recurring topics focused on the green turtle fishery

Experts and key local collaborators were interviewed indepth on specific topics related to green turtle fishing or abundance (e.g.: fishing gear, green turtle commerce, etc.)

Focus group discussions with members of a fishing crew to discuss how green turtle abundance changed over the course of their careers

Interviewing experts on their life history and their experience as green turtle fishers

Visiting key green turtle fishing spots and recording coordinates with GPS

Documenting kinship and work relations among green turtle fishers and merchants

Analyzing discourse on regulation or conservation to identify biases that could affect how fishers report on turtle catches
Practical implications

All observations are compiled in field notes and journals, including, but not limited to research topics

Recorded in field notes and field journals

Recorded in audio or video with the collaborators' consent

Recorded in audio or video with the collaborators' consent

Recorded in audio or video with the collaborators' consent

Recorded in audio or video with the collaborators' consent

Recorded in notes, digital maps, GIS or printed maps

Recorded in notes and graphs

Analysis of ethnographic materials; feedback integrated into new questions

Sources: Bernard, 2011; Crandall, 2018; Early-Capistrán et al., 2018 


\section{Table 2 (on next page)}

Tools and criteria for the model fitting and selection processes

Throughout the iterative process, we used nonlinear regression to describe catch-per-uniteffort trends over time, and generalized linear models to identify significant predictor variables. Residual analyses were used to ensure that model assumptions were met, and to evaluate goodness of fit and robustness. 
1

\begin{tabular}{|c|c|c|c|}
\hline Process & Software & Model selection criteria & Residual analyses \\
\hline $\begin{array}{l}\text { Preliminary model } \\
\text { selection and starting } \\
\text { values }\end{array}$ & LABFit 7.2 .49 & $\mathrm{R}^{2}$ value & --- \\
\hline $\begin{array}{l}\text { Nonlinear Regression } \\
\text { (NLR) }\end{array}$ & $\begin{array}{l}\mathrm{R} 3.4 \text { (nlstools } \\
\text { and easynls } \\
\text { package) }\end{array}$ & $\begin{array}{l}R^{2} \text { value } \\
\text { Robust residuals: } \\
e_{i} \sim N\left(0, \sigma^{2}\right)\end{array}$ & $\begin{array}{l}\text { Normality: } \\
\text { Shapiro-Wilk test, } p>0.05 \\
\text { Mean }=0 \text { : } \\
\text { t-test, } p>0.05 \\
\text { Homogeneity of variance: } \\
\text { Levene's test, } p>0.05 \\
\text { Randomness: } \\
\text { runs test, } p>0.05 \\
\text { Auto-correlation: } \\
\text { Pearson correlation test } \\
\text { (residuals vs. lagged } \\
\text { residuals), } p>0.05 \\
\text { (i.e., } H_{0}: \rho=0, H_{a}: \rho \neq 0 \text { ) }\end{array}$ \\
\hline $\begin{array}{l}\text { Generalized Linear } \\
\text { Model (GLM) }\end{array}$ & $\begin{array}{l}\text { R } 3.4 \text { (nlme, } \\
\text { Imtest and car } \\
\text { packages) }\end{array}$ & $\begin{array}{l}\text { Significant predictor } \\
\text { variables }(p<0.05) \\
D^{2} \text { value } \\
\text { Low relative AIC } \\
\text { Robust residuals: } \\
e_{i} \sim N\left(0, \sigma^{2}\right)\end{array}$ & $\begin{array}{l}\text { Normality: } \\
\text { Shapiro-Wilk test, } p>0.05 \\
\text { Mean }=0 \text { : } \\
\text { t-test, } p>0.05 \\
\text { Homogeneity of variance: } \\
\text { Levene's test, } p>0.05 \\
\text { Randomness: } \\
\text { runs test, } p>0.05 \\
\text { Auto-correlation: } \\
\text { Durbin-Watson test, } \\
p>0.05\end{array}$ \\
\hline
\end{tabular}


Table 3 (on next page)

Variables, coefficients, and indices 
1

\begin{tabular}{|c|c|c|c|}
\hline $\begin{array}{l}\text { Variable or } \\
\text { coefficient }\end{array}$ & Type & Index & Source \\
\hline Year of birth & Numerical & Date & Standard question in interviews \\
\hline $\begin{array}{l}\text { Dates working in } \\
\text { the green turtle } \\
\text { fishery }\end{array}$ & Range & Interval of dates & Standard question in interviews \\
\hline $\begin{array}{l}\text { Experience in the } \\
\text { green turtle fishery }\end{array}$ & Ordinal & $\begin{array}{l}1=1-5 \text { years } \\
2=6-10 \text { years } \\
3=11-15 \text { years }\end{array}$ & $\begin{array}{l}\text { Binned from dates working in the } \\
\text { fishery }\end{array}$ \\
\hline Generation & Categorical & $\begin{array}{l}1=\text { Fishers who worked in } \\
\text { commercial development and } \\
\text { commercial fishing stages } \\
2 \text { = Fishers who worked during } \\
\text { the collapse stage } \\
3=\text { Fishers who worked through } \\
\text { all stages }\end{array}$ & $\begin{array}{l}\text { Category of cohorts of fishers } \\
\text { defined based on the fishery stages } \\
\text { in which the contributor worked }\end{array}$ \\
\hline Fishery stage & Categorical & $\begin{array}{l}1=\text { Commercial development } \\
2=\text { Commercial fishing (harpoon) } \\
3=\text { Commercial fishing (nets) } \\
4=\text { Collapse }\end{array}$ & $\begin{array}{l}\text { Defined based on qualitative data } \\
\text { on the fishery }\end{array}$ \\
\hline Year & Numerical & $\begin{array}{l}\text { Date for which the average } \\
\text { CPUE is being described }\end{array}$ & $\begin{array}{l}\text { Obtained directly from interviews } \\
\text { (numerical value) or calculated } \\
\text { based on heuristic rules (details in } \\
\text { S.I.) }\end{array}$ \\
\hline Fishing gear & Ordinal & $\begin{array}{l}1=\text { Harpoon } \\
2=\text { Short set-net }(\sim 100 \mathrm{~m}) \\
3=\text { Long set-net }(\sim 200 \mathrm{~m})\end{array}$ & $\begin{array}{l}\text { Binned from interviews or inferred } \\
\text { based on heuristic rules }\end{array}$ \\
\hline $\begin{array}{l}\text { Harpooner skill } \\
\text { coefficient }\end{array}$ & Percentage & $\begin{array}{l}\text { Percentage of success } \\
(50-99 \%)^{a}\end{array}$ & $\begin{array}{l}\text { Obtained from interview data and } \\
\text { assigned to contributors based on } \\
\text { social network analysis }\end{array}$ \\
\hline Number of nets & Numerical & Number of nets used ${ }^{b}$ & $\begin{array}{l}\text { Obtained directly from interviews or } \\
\text { inferred based on heuristic rules }\end{array}$ \\
\hline Vessel type & Ordinal & $\begin{array}{l}\text { Type of vessel used } \\
1=\text { Wooden canoe }(12-15 \mathrm{ft} \\
\text { length) } \\
2 \text { = Fiberglass skiff ( } 20-22 \mathrm{ft} \\
\text { length) } \\
3 \text { = Boat (variable length) }\end{array}$ & $\begin{array}{l}\text { Binned from interviews or inferred } \\
\text { based on heuristic rules }\end{array}$ \\
\hline Vessel capacity & Ordinal & $\begin{array}{l}\text { Gross vessel tonnage } \\
1=\text { Less than } 1 \text { ton } \\
2=1-1.5 \text { tons } \\
3=\text { Greater than } 1.5 \text { tons }\end{array}$ & $\begin{array}{l}\text { Binned from interviews or inferred } \\
\text { based on heuristic rules }\end{array}$ \\
\hline Propulsion ${ }^{\mathrm{c}}$ & Categorical & $\begin{array}{l}1=\text { Oars } \\
2=\text { Motor }(5-10 \text { horse-power }) \\
3=\text { Motor (15-40 horse-power) }\end{array}$ & $\begin{array}{l}\text { Obtained directly from interviews or } \\
\text { inferred based on heuristic rules }\end{array}$ \\
\hline Trip duration ${ }^{\mathrm{c}}$ & $\begin{array}{l}\text { Numerical or } \\
\text { interval }\end{array}$ & $\begin{array}{l}\text { Number of days between leaving } \\
\text { port and returning with a catch of } \\
\text { turtles at vessel capacity } \\
\text { Minimum limit: } 1 \text { day } \\
\text { Maximum limit: } 10 \text { days }\end{array}$ & $\begin{array}{l}\text { Obtained directly from interviews or } \\
\text { inferred based on heuristic rules } \\
\text { (S.I., Eqn. S1, S2) }\end{array}$ \\
\hline Fishing time & Numerical & $\begin{array}{l}\text { Number of nights spent fishing on } \\
\text { a trip of regular duration }\end{array}$ & $\begin{array}{l}\text { Obtained directly from interviews or } \\
\text { inferred based on heuristic rules } \\
\text { (S.I., Eqn. S1, S2) }\end{array}$ \\
\hline Average CPUE & Numerical & $\begin{array}{l}\text { Average number of turtles caught } \\
\text { in one night during a specific year }\end{array}$ & $\begin{array}{l}\text { Obtained directly from interviews } \\
\text { (numerical value) or calculated } \\
\text { based on heuristic rules }\end{array}$ \\
\hline
\end{tabular}


Table 4 (on next page)

Fishery stages and characteristics 


\begin{tabular}{|c|c|c|c|c|}
\hline & $\begin{array}{l}\text { Commercial } \\
\text { development } \\
(1950-1959)\end{array}$ & $\begin{array}{l}\text { Commercial } \\
\text { fishing (harpoons) } \\
(1960-1965)\end{array}$ & $\begin{array}{l}\text { Commercial fishing } \\
\text { (nets) } \\
(1966-1972)\end{array}$ & $\begin{array}{l}\text { Collapse } \\
(1974-1982)\end{array}$ \\
\hline $\begin{array}{l}\text { General } \\
\text { characteristics }\end{array}$ & $\begin{array}{l}\text { First years of the } \\
\text { commercial fishery, } \\
\text { with limited } \\
\text { technology and } \\
\text { fishing effort }\end{array}$ & $\begin{array}{l}\text { Intense growth in } \\
\text { demand leads to } \\
\text { declining captures }\end{array}$ & $\begin{array}{l}\text { Increasing fishing } \\
\text { effort and efficiency, } \\
\text { declining captures }\end{array}$ & $\begin{array}{l}\text { Commercial } \\
\text { collapse. Species } \\
\text { abundance near } \\
\text { extinction. }\end{array}$ \\
\hline Regulation & Unregulated & Unregulated & $\begin{array}{l}\text { Limited regulation: } \\
\text { minimum size, permit } \\
\text { restrictions, seasonal } \\
\text { bans } \\
\text { Temporary ban } \\
(1971)\end{array}$ & $\begin{array}{l}\text { Highly regulated: } \\
\text { minimum size, } \\
\text { permit restrictions, } \\
\text { seasonal bans, } \\
\text { nesting beach } \\
\text { protection (1980- } \\
\text { present) } \\
\text { Green turtle } \\
\text { licenses } \\
\text { suspended (1983) }\end{array}$ \\
\hline Gear type & Harpoons & Harpoons & Set-nets & Set-nets \\
\hline $\begin{array}{l}\text { Fleet } \\
\text { conditions }\end{array}$ & $\begin{array}{l}\text { Wooden canoes } \\
\text { Oars or paddles }\end{array}$ & $\begin{array}{l}\text { Wooden canoes } \\
5-10 \text { horse-power } \\
\text { outboard motors }\end{array}$ & $\begin{array}{l}\text { Canoes or skiffs } \\
5-10 \text { horse-power } \\
\text { outboard motors }\end{array}$ & $\begin{array}{l}\text { Fiberglass skiffs } \\
15-45 \text { horse-power } \\
\text { outboard motors }\end{array}$ \\
\hline $\begin{array}{l}\text { Spatial } \\
\text { distribution of } \\
\text { fishing }^{a}\end{array}$ & $\begin{array}{l}\text { Overnight trips close } \\
\text { to port are frequent }\end{array}$ & $\begin{array}{l}\text { Motors allow faster } \\
\text { displacement to } \\
\text { farther fishing } \\
\text { grounds } \\
\text { Occasional trips } \\
>50 \text { nautical miles }\end{array}$ & $\begin{array}{l}\text { Trips }>50 \text { nautical } \\
\text { miles are frequent } \\
\text { Expeditions }>100 \\
\text { nautical miles are } \\
\text { frequent (canoes or } \\
\text { skiffs off-loading to } \\
\text { boats) }\end{array}$ & $\begin{array}{l}\text { Trips }>50 \text { nautical } \\
\text { miles are frequent }\end{array}$ \\
\hline $\begin{array}{l}\text { Size } \\
\text { distribution b }\end{array}$ & $\begin{array}{l}\text { Turtles } 150 \mathrm{~kg} \\
\text { caught frequently } \\
\text { (spans of } \\
\text { weeks/months) } \\
\text { Mode weight: } 50 \mathrm{~kg}\end{array}$ & $\begin{array}{l}\text { Turtles } 150 \mathrm{~kg} \\
\text { caught frequently } \\
\text { (spans of } \\
\text { weeks/months) } \\
\text { Mode weight: } 50 \mathrm{~kg}\end{array}$ & $\begin{array}{l}\text { Turtles } 100-150 \mathrm{~kg} \\
\text { caught occasionally } \\
\text { (spans of } \\
\text { seasons/years) } \\
\text { Mode weight: } 50 \mathrm{~kg}\end{array}$ & $\begin{array}{l}\text { Turtles } 100-150 \mathrm{~kg} \\
\text { caught rarely } \\
\text { (spans of years) } \\
\text { Mode weight: } 50 \mathrm{~kg}\end{array}$ \\
\hline $\begin{array}{l}\text { Fishing } \\
\text { efficiency }\end{array}$ & Low & Low/Moderate & Moderate & High \\
\hline Fishing effort & Low & High & High & Low \\
\hline $\begin{array}{l}\text { Commercial } \\
\text { demand }\end{array}$ & Moderate & High & High/moderate & Moderate \\
\hline Profitability & High & High & High/Declining & Not profitable \\
\hline \multicolumn{5}{|c|}{$\begin{array}{l}\text { a Throughout the chronology, spatial distribution of fishing was highly variable due to the targeting of hot-spots } \\
\text { and variations in the seasonal distribution of turtles } \\
\text { b Size distribution was highly variable throughout the chronology } \\
\text { Characteristics from qualitative LEK and Early-Capistrán et al. (2019), Márquez (1996), and Seminoff et al. } \\
\text { (2008) }\end{array}$} \\
\hline
\end{tabular}




\section{Table 5 (on next page)}

Generalized linear model (GLM) results for the raw catch-per-unit-effort (CPUE) database

The three most parsimonious GLMs for the raw database suggested that fishing gear type, vessel capacity, and number of nets were significant predictor variables for CPUE. Italics indicate significant results at $\alpha=0.95$. Asterisks indicate significant result at $\alpha=0.90$; this variable was included to ensure robust residuals. 


\begin{tabular}{|c|c|c|c|}
\hline Predictors & Estimate & Std. error & P-value \\
\hline \multicolumn{4}{|c|}{$\begin{array}{l}\text { Model 1: } \log (\text { cpue }) \sim \text { Year serial + Experience + Vessel Capacity }-1 ; \text { AIC: } 4.422 ; D^{2}=0.775 ; d f=32 ; \\
e_{i} \sim N\left(0, \sigma^{2}\right) \\
\text { Correlation Structure: Auto-regressive, Formula: } \sim \text { Year Serial }\end{array}$} \\
\hline Year (serialised) & -0.278 & 0.00434 & 0.000 \\
\hline Experience & 0.333 & 0.0328 & 0.000 \\
\hline Vessel Capacity & 0.330 & 0.0692 & 0.000 \\
\hline \multicolumn{4}{|c|}{$\begin{array}{l}\text { Model 2: } \log (\text { cpue }) \sim \text { Year serial }+ \text { Gear }+ \text { Total Net Length }+ \text { Number of Nets }+ \text { Experience }-1 ; \\
\text { AIC: } 10.215 ; D^{2}=0.925 ; d f=20 ; e_{i} \sim N\left(0, \sigma^{2}\right) \\
\text { Correlation Structure: Auto-regressive, Formula: } \sim \text { Year Serial }\end{array}$} \\
\hline Year (serialised) & -0.0239 & 0.0061 & 0.0014 \\
\hline Gear Type & 0.396 & 0.0980 & 0.0011 \\
\hline Total Net Length & -0.150 & 0.0429 & 0.0033 \\
\hline Number of Nets & 0.238 & 0.0750 & 0.0062 \\
\hline Experience & 0.0969 & 0.0494 & $0.0689^{*}$ \\
\hline
\end{tabular}

Model 3: $\log ($ cpue $) \sim$ Year serial + Gear + Net Length $-1 ;$ AIC: $-11.710 ; D^{2}=0.971 ; d f=32 ; e_{i} \sim N\left(0, \sigma^{2}\right)$ Correlation Structure: Auto-regressive, Formula: $\sim$ Year Serial

$\begin{array}{llll}\text { Year (serialised) } & -0.0284 & 0.00465 & 0.000 \\ \text { Gear type } & 1.324 & 0.0689 & 0.000 \\ \text { Net Length } & -1.321 & 0.0680 & 0.000\end{array}$




\section{Table 6(on next page)}

Results of nonlinear regression with best fit for catch-per-unit-effort estimates derived from local ecological knowledge

Italics indicate significant results at $\alpha=0.95$. See also Figure 6 . 
1

$\begin{array}{llllll}\text { Parameter } & \text { Estimate } & \text { Std. error } & 95 \% \text { C.I. } & \text { t-value } & \text { P-value } \\ \alpha \alpha & 24.112 & 3.124 & {[17.413-30.812]} & 7.719 & 2.07 e-06 \\ \beta & -0.0829 & 0.0130 & {[-0.111-(-0.0551)]} & -6.382 & 1.71 e-05\end{array}$

Model: $Y \sim \alpha \cdot e^{(\beta x)} ; d f=14 ; e_{i} \sim N\left(0, \sigma^{2}\right)$

2 


\section{Figure 1}

Overview of methodological processes used to document, synthesize and quantify Local Ecological Knowledge (LEK).

The upper box illustrates the iterative process described in Phases 1 and 2. This includes LEK documentation and synthesis; analysis with descriptive statistics, generalized linear models (GLMs), and nonlinear regression (NLR); and integration of feedback from statistical analyses and local collaborators. This iterative process was repeated until reaching topical, thematic, and data saturation, and until model fitting did not provide significant new information. The lower box illustrates catch-per-unit-effort (CPUE) data standardization (Phase 3). The raw database (Section 3.1) contained average, representative CPUE values for a given year, and heterogeneous descriptor variables. We standardized CPUE values using GLMs (Section 3.2) to (i) remove most of the variation not attributable to changes in abundance, and (ii) generate CPUE values that could be compared over time. 


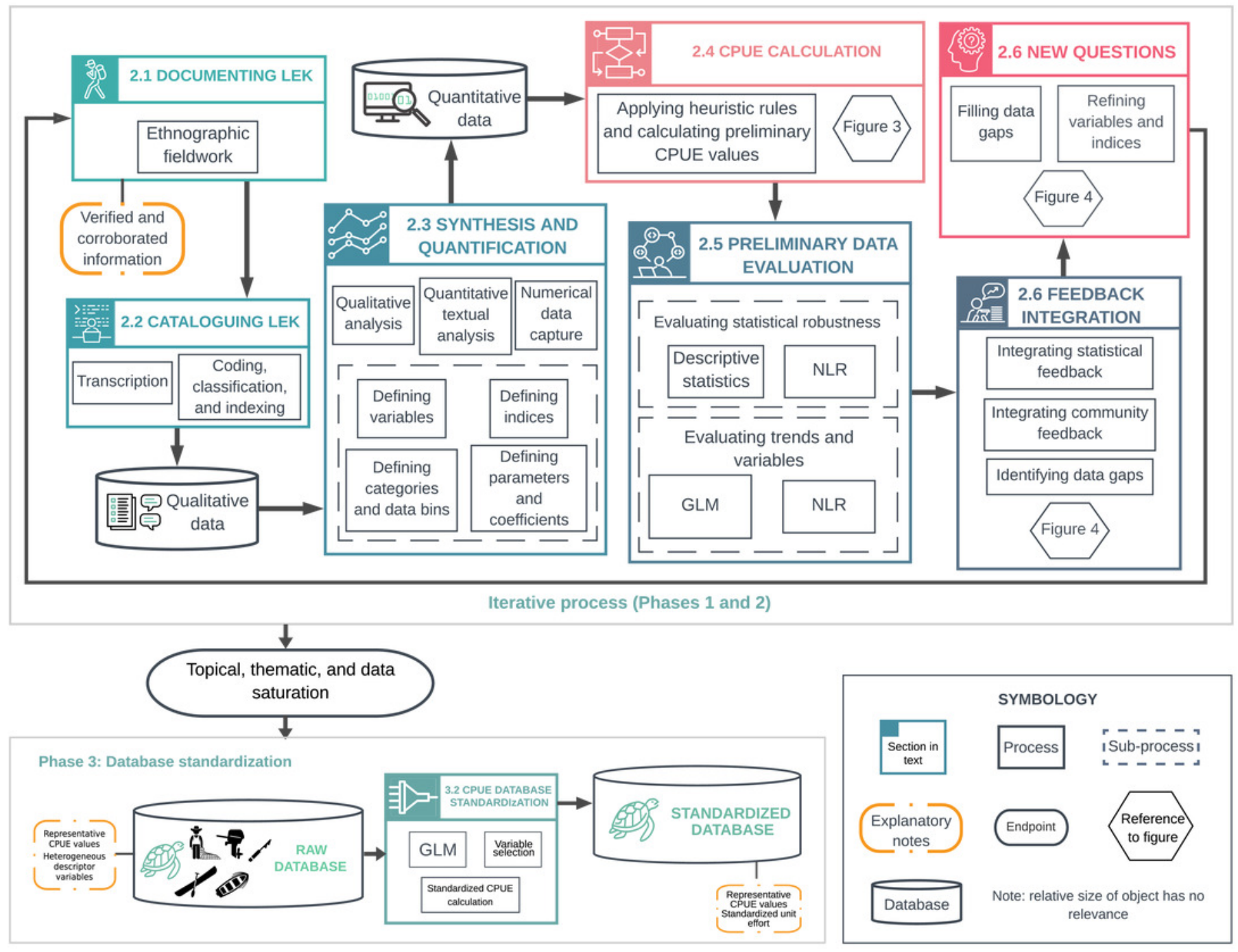




\section{Figure 2}

Biocultural consensus as a synergy of interconnected knowledge (adapted from Brown, 2010).

Biocultural consensus was constructed with multiple and complementary contents and knowledge types from three different social groups. Sample sizes, ethnographic methods, and interview methods used with each group are provided. The target population of turtle fishers were the group with which we collaborated most intensively and which provided the majority of LEK, as well as qualitative and numerical data. Turtle fishers' knowledge was complemented with knowledge from of key local collaborators and community members. Biocultural consensus helped build conceptual frameworks for modelling, establish limits and assumptions, estimate model parameters, and validate model outputs. 


\section{Key}

Distance from center indicates relative input of each group/knowledge type

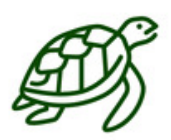

GREEN TURTLE ABUNDANCE

Index: Catch-per-unit-effort

Quantitative data synthesized from

biocultural consensus

\section{SPECIALIZED LEK \\ Primary data source}

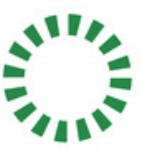

Green turtle fishers $(n=16)$

Methods: Semi-structured interviews, indepth interviews, informal interviews, participant observation, focus groups, social network analysis

\section{SPECIALIZED LOCAL}

\section{COMMUNITY KNOWLEDGE}

\section{Contextual data}

Key local collaborators with specialized knowledge $(n=7)$

Methods: In-depth interviews, informal interviews, participant observation

\section{COMMUNITY KNOWLEDGE \\ Complementary data}

Multiple perspectives from members of the community at large $(n=48)$

Methods: Informal interviews, participant observation

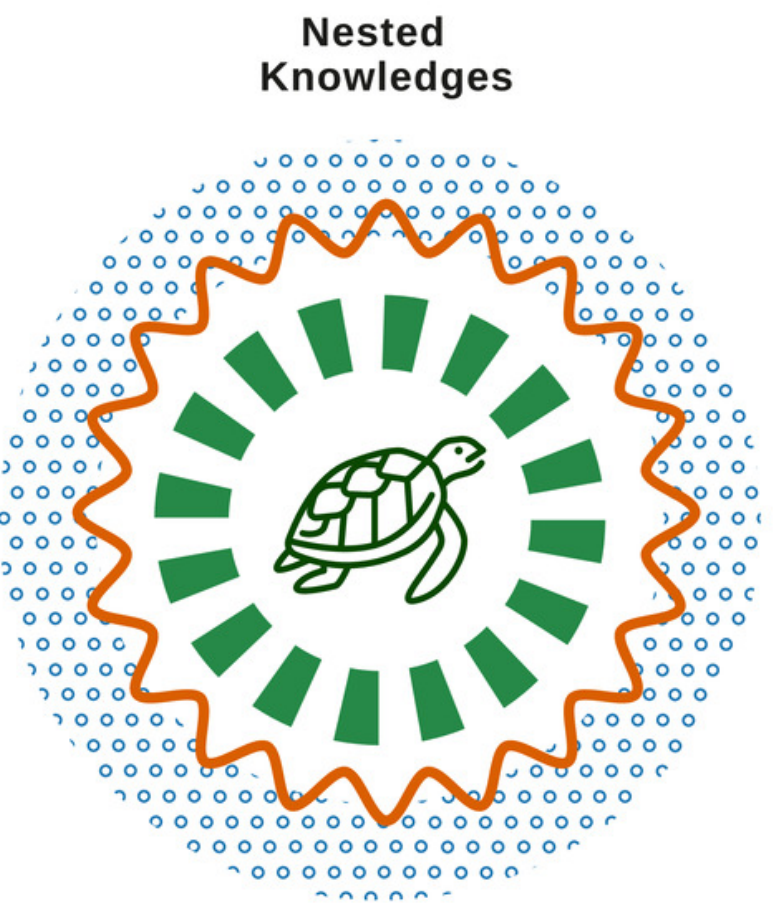

BIOCULTURAL CONSENSUS

Knowledge from multiple groups generates a synergy from which quantitative data is synthesized. 


\section{Figure 3}

Heuristic rules used to make systematic inferences based on expert knowledge to calculate raw catch-per-unit-effort values.

We used heuristic rules to make systematic inferences based on the knowledge of expert turtle fishers (Phase 2, Section 2.4). This framework allowed us to reduce individual cognitive bias by (i) complementing the knowledge of less experienced fishers with that of experts, and (ii) calculating a central tendency based on collectively-generated knowledge and biocultural consensus.

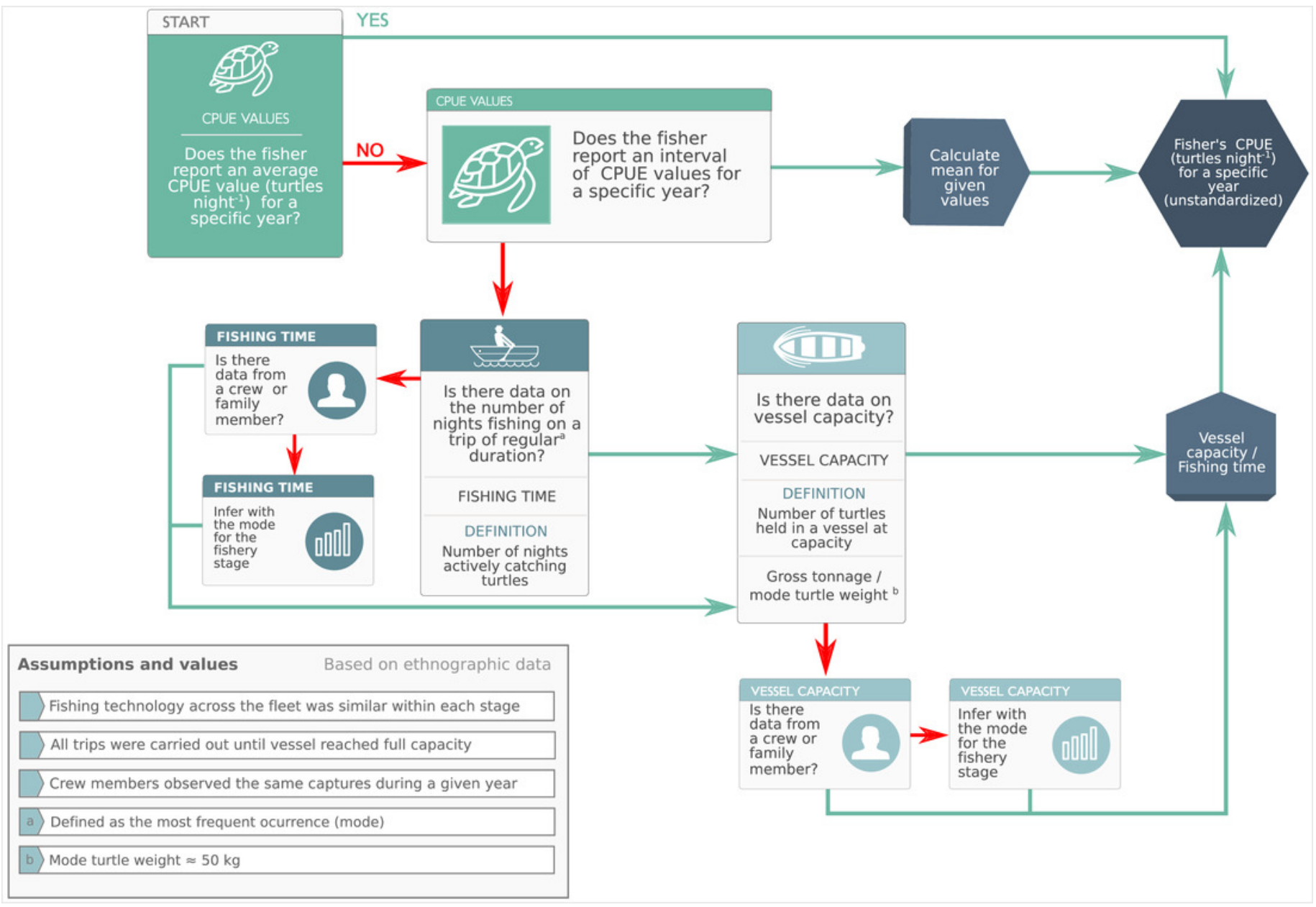




\section{Figure 4}

\section{Cyclical process of index design and feedback integration}

We revised indices and coefficients based on a cyclical process which used feedback from interviews, statistical analysis, and generalized linear models (GLMs) to design new questions. This was repeated for each variable throughout Phase 2. Bold type shows numerical data from interviews.

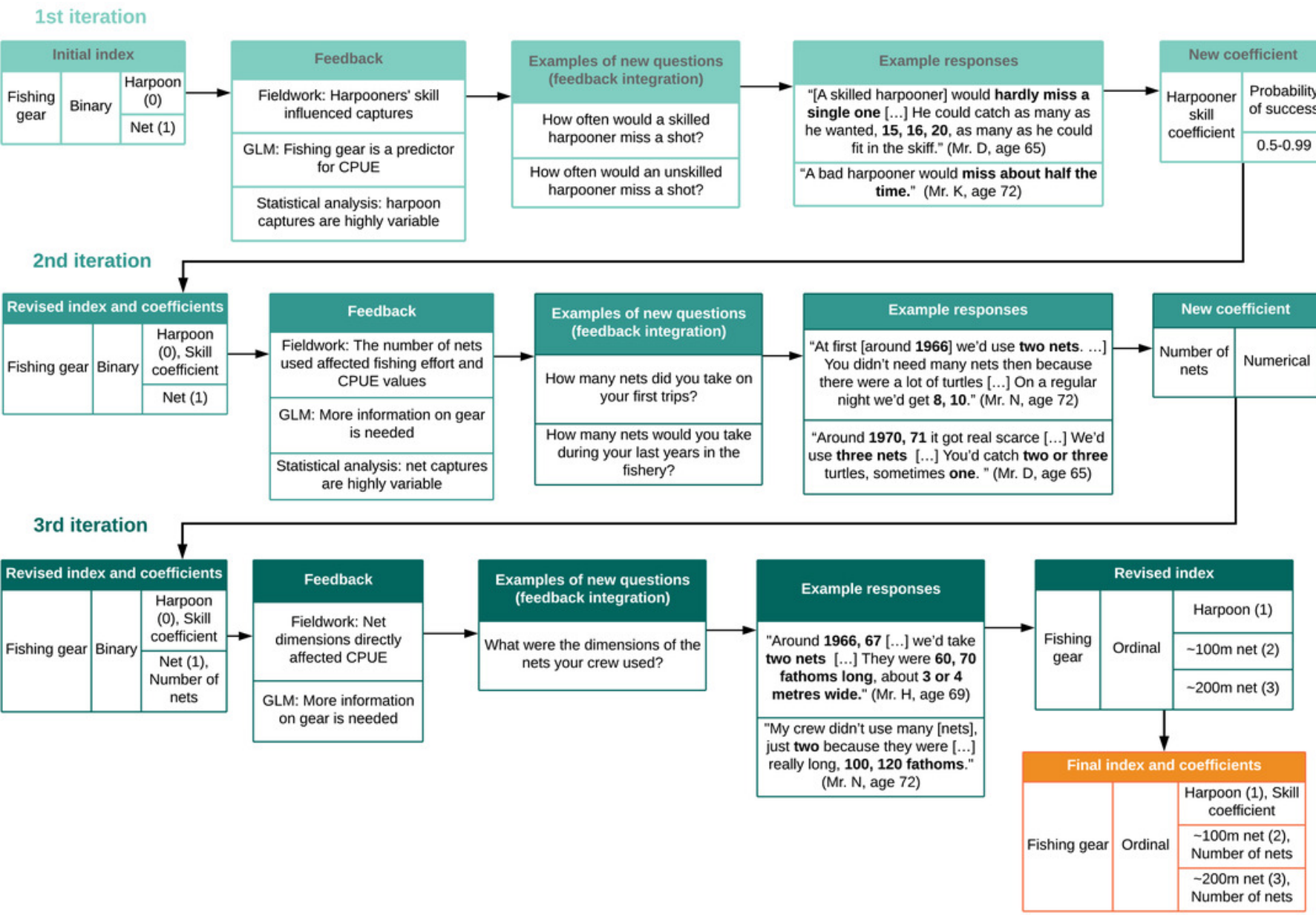




\section{Figure 5}

Exponential decay model fitted to standardized catch-per-unit-effort (CPUE) values for C. mydas in Bahías de los Ángeles, derived from local ecological knowledge (LEK).

Data points are mean, standardized LEK-derived CPUE values for a specific year (red triangles and dotted line; left Y-axis) and total annual landings from available fisheries statistics for Bahía de los Ángeles (blue circles and dotted line; right Y-axis) (Márquez in Seminoff et al., 2008). Curves represent suggested trends based on an exponential decay model (details in SI: Article S1). Lin Concordance Correlation Coefficient of paired z-scores suggests strong agreement between datasets (see also SI: Figure S6). 


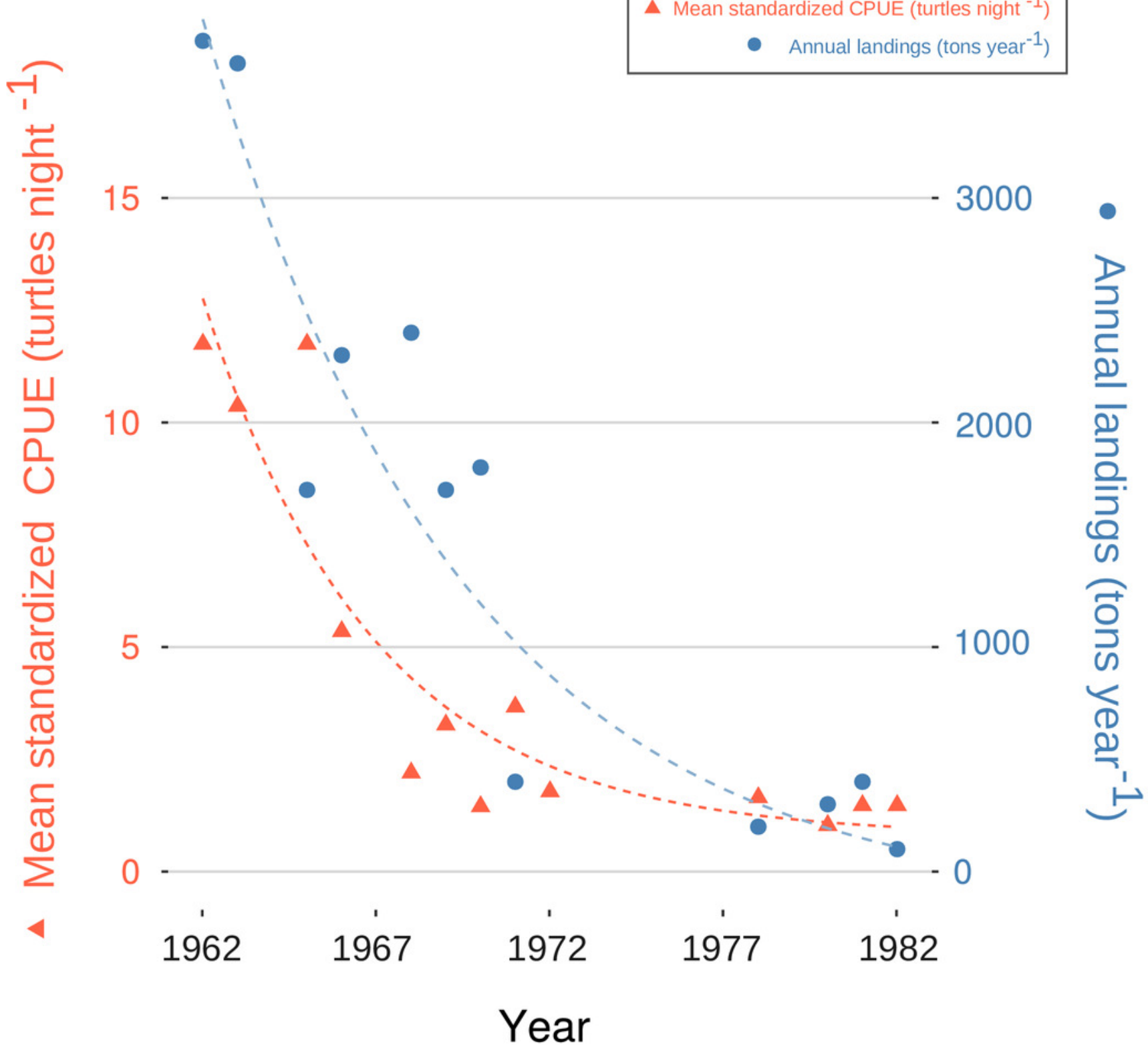




\section{Figure 6}

Exponential decay model fitted to mean, standardized catch-per-unit-effort (CPUE) values for $C$. mydas in Bahía de los Ángeles, derived from local ecological knowledge (LEK).

Curve represents the nonlinear regression with best fit and robust residuals, based on an exponential decay model. Each data point is a representative, mean, standardized CPUE value for a specific year derived from LEK data. Colors represent fishery stages (see Table 4). Parameter values, standard error, confidence intervals, t-values, and P-values can be found in Table 6. 


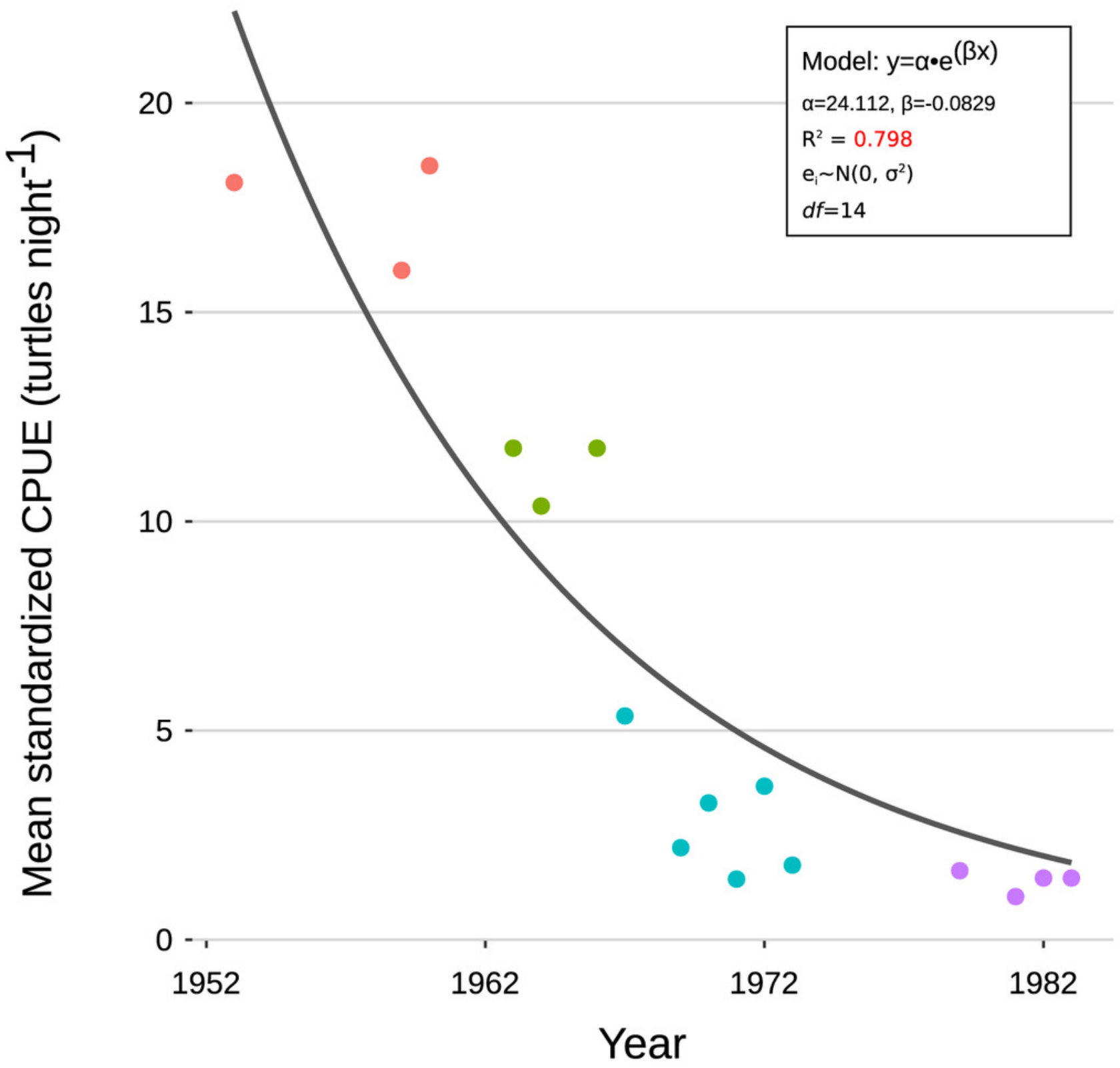

Fishery Stage

Commercial development

Commercial fishing (nets)
Commerical fishing (harpoon)

Collapse 